Revised

March 21, 2010

\title{
Global crisis and national policy responses: together alone?
}

\author{
Jorge Braga de Macedo \\ Lisbon Academy of Science (ACL)
}

\section{INTRODUCTION}

With the oil crises of the 1970s and the breakdown of the Bretton Woods system of fixed exchange rates, macroeconomic policy coordination was invoked almost exclusively among the increasingly interdependent economies of the OECD. Leaders of France, Germany, Italy, Japan, the United Kingdom and the United States first met at Rambouillet, being joined by Canada in 1976 to form the G-7. Finance ministers and central bank governors of the G7 informally coordinated OECD and IMF multilateral surveillance activities. In the wake of the 1997 Asian financial crisis, finance officials from about 20 major advanced and emerging countries "discussed measures to promote the financial stability of the world and to achieve a sustainable economic growth and development". When Russia's leader joined the G7, it became the G8 and summit chairs began to invite major emerging countries. Moreover Canada called for leaders of the 20 countries to meet on cross cutting issues as needed ${ }^{2}$. As it turns out, the first G-20 summit was held in Washington in December 2008 to deal with the financial crisis even though it also sought to preserve the multilateral trade system. There were follow up meetings on macroeconomic stimulus packages in London and Pittsburgh, where the so called Washington consensus of the 1990s was "pronounced dead" and the IMF received a renewed mandate for comparative analysis.

\footnotetext{
${ }^{1}$ An earlier version was presented at Faculdade de Ciências Sociais e Humanas, Universidade Nova de Lisboa, on 13 October 2009 at a Philosophy Department conference organized by my ACL colleague Michel Renaud and by Gonçalo Marcelo. Since I first used the title of the Crowded House song recorded in New Zealand in 1992 in remarks at a dinner on 25 September 2008 for London Business School alumni in Lisbon, I have received many comments on this material. I acknowledge especially an entrepreneurial motivation course in mid-August at a neighbor's home in Almoçageme, Sintra (available at www.jbmacedo.com/ferragosto); a course on Development and state reform at Instituto de Estudos Superiores Militares, Pedrouços, 17 September; the Center for International Governance Innovation (CIGI) meeting, "Towards a global new deal", Waterloo, Ontario, on 2 October, the Launch Conference for Initiative for Development and Global Governance (IDGM), Paris, 6 November; Les Rencontres Jean Monnet des Fondations Européennes, Cognac 14 November; Waterland Ten Years After, Institut FrancoPortugais, Lisbon, 17 November; Clube Tauromáquico, Lisbon, 18 November; the IV Annual Specialization Course for Young Ibero-American Diplomats, Secretariado Geral Ibero Americano (SEGIB), Lisbon, 3 December; special session on Europe, ACL, February 11. See note 36 below.

${ }^{2}$ In addition to the website of the Korean presidency in 2010 (www.g20.org), the University of Toronto maintains a website about the G8 and CIGI was at the forefront of the G20 at leaders' level. The OECD Development Center attempted to follow G20 finance work, see Macedo et al. (2001) and OECD (2003).
} 
After decades when failures of coordination within and between advanced countries, even within an increasingly integrated EU, were seen with benign neglect, governments had to face together a financial crisis that their nations addressed alone. Actually this paradox in the interaction between globalization and governance $(G \& G)$ arose within the euro area itself. There policy coordination is supposed to be strongest, even before the Lisbon treaty gave a formal role to the finance ministers of its member countries, alongside those of the EU - who were signatories of the Maastricht treaty in 1992. Independently of joint appearances at the G-20 summits, following enlarged G-8 events, developed countries and emerging markets realize that they are mutually interdependent even though they rarely coordinate their national policy responses, making the "together alone" as global as the crisis.

The trade and financial links between the United States and China, sometimes called the G-2, are the most vivid example but the differences in the perception of the financial crisis of 2007/2008 by the Queen of England and the President of Brazil are equally striking. On a visit to the London School of Economics on 5 November, 2008, Queen Elizabeth asked Luis Garicano: "if these things were so large, how come everyone missed them?" During a subsequent visit to Brazil of her Prime Minister, President Lula made an equally celebrated comment: the crisis originating in rich countries is "a blue-eyed crisis". There have been responses to the question in the form of letters, whereas the comment has been neglected as a kind of ethnic joke. Nevertheless, the implicit exchange between Queen and President underscores the cultural dimension of the "together alone" paradox: no one saw the global crisis coming because everyone who could see suppressed a (blue-eyed) crisis. This tendency for "group think" cannot be ignored "in a world that is both highly connected and tribal" 3 . In any event, the British Academy responded to the Queen's question on 17 June, 2009 by convening a "Forum" on the crisis chaired by Peter Hennessy where Charles Goodhart opened the discussion and the Forum chair and Tim Besley signed the letter on $22 \mathrm{July}^{4}$.

A second "Forum" on the subject was held on 15 December 2009, and another letter sent on 8 February, 2010, investigating "financial and economic horizon-scanning capabilities". The second letter was more critical of the UK government precisely because "the major challenge is to make institutions and organizational cultures work together. This means also getting the right people involved who see the task as a central part of their role in government. One can have as much scenario planning as one likes,

\footnotetext{
${ }^{3}$ Gillian Tett, Financial Times, 9 October, 2009 - who refers to this as the "silo curse".

${ }^{4}$ The first Forum met on 19 March to discuss The Strange Career of British Democracy. Hennessy is Queen Mary University of London professor of contemporary British history and former journalist; Goodhart is Emeritus LSE professor of banking and finance and former chief economic advisor to the Bank of England; Besley is Professor of economic development at LSE, director of The Suntory and Toyota International Centre for Economics and Related Disciplines and former member of the monetary policy committee of the Bank of England. David Turner, FT education correspondent, wrote "Credit crunch failure explained to Queen" (FT.com, 26 July). The website of the British Academy quoted its chief executive and secretary: "The global recession is a huge development, and it is reasonable to ask to what extent it could have been foreseen. What's more, we can't say 'never again' if we don't fully understand what occurred". The Queen's Private Secretary wrote back on 30 July, indicating her interest in the project.
} 
but if there is no buy in from the people who will be taking the decisions in a crisis, then it is probably counterproductive" 5 .

This paper contends that the G\&G paradox revealed by the global crisis is rooted in "group think" within and between countries. In spite of peer review mechanisms at the OECD and the EU, and of international governance innovation such as the "global partnership for development" (and the seven other Millennium Development Goals MDGs), not enough attention was paid to common problems among advanced countries, including financial regulation and supervision in the face of rising asset prices. Increased trade in goods, services and assets led to rising global imbalances between the US and emerging markets with currencies pegged to the dollar, especially China. The resulting volatility in prices of oil and staples had severe implications for poverty alleviation and food security, making the seven quantified MDGs impossible to reach in 2015, especially in the African Union (AU), where a peer review mechanism has been operating for almost ten years. The argument in section 2 embeds the letters to the Queen into a renewed interest in methodology which goes beyond recurrent calls for interdisciplinary research - as long as this research does not disturb the usual "economists tribes", a point that comes across more clearly in the second letter. Noting failures of cooperation within and between countries, section 3 applies a perspective based on G\&G interaction to the "together alone" paradox. It introduces mutual knowledge as essential for the global partnership on development and presents in that connection the experience of culturebased multilateralism among members of the Community of Portuguese-speaking Countries (CPLP).

Drawing on a comparison of multilateral surveillance frameworks, section 4 focuses on Europe as an example of regional governance where peer pressure stems from explicit commitments ${ }^{6}$. While peer reviews need not promote the common good, which requires a combination of greater integration and flexibility, applications of multilateral surveillance beyond OECD members and the emerging G20 may turn out to be international governance innovations. The concluding section 5 notes the IMF mandate from

\footnotetext{
${ }^{5}$ The second letter ended with a proposal that caught the attention of the media: "If you, Your Majesty, were to ask for a monthly economic and financial horizon-scanning summary from, say, the Cabinet Office, it could hardly be refused. It might take a form comparable to the Joint Intelligence Committee's 'Red Book', which you received each week from 1952 until 2008 when it was abandoned. And, if this were to happen, the spirit of your LSE question would suffuse still more those of your Crown servants tasked to defend, preserve and enhance the economic well-being of your country". This has not yet brought a response but was followed by a debate on exit strategies from the fiscal stimulus, in letters to the Sunday Times of February 14 by Besley and others suggesting an early exit followed by letters to the Financial Times of February 19 arguing against it. The UK electoral campaign thus begins with "a fiscal battle" among economists, very much along the lines of the "together alone" paradox described in the text.

${ }^{6}$ Thygesen (2002) compares IMF, OECD and EU. Macedo (2003) adds the New Partnership for African Development (NEPAD), established with the formal adoption of the Strategic Framework at the 37th Summit of the Organization for African Unity in July 2001 now being integrated in the AU structures and processes and called NEPAD Planning and Coordinating Agency. The integrated socio-economic development framework proposed by the leaders of Algeria, Egypt, Nigeria, Senegal and South Africa established a secretariat in Pretoria. Macedo (2003) also includes case studies in mutual knowledge: social dialogue in Mozambique (Mantero and Santos 2002) and post-conflict transition in the Democratic Republic of Congo (Castillo, 2003); see NEPAD (2001), UNECA (2002) and (Kanbur, 2004).
} 
"Framework for Strong, Sustainable, and Balanced Growth" approved at the Pittsburgh. It remains to be seen whether multilateral surveillance mechanisms reflect the mutual accountability contained in the Monterey declaration of February 2002 which was supposed to replace the so called Washington consensus. If so, the G20 might bring out coalitions where peer pressure is for action, not for inaction, so that G\&G interaction becomes positive on a broader front.

\section{DECONSTRUCTING THE LETTERS TO THE QUEEN}

\section{1. "Economic culture wars" revisited}

If the G20 enhances the multilateral surveillance framework of the IMF in the direction of mutual accountability, coalitions among nations and regions will have beneficial consequences for the global common good and may reflect positively on the role of economists in public life. At the moment, the field is full of controversy: on October 12, the day the Nobel prize in economics was announced, a "global insight" by Alan Beattie appeared in the Financial Times about the bickering between freshwater (e.g. Chicago) and saltwater (e.g. MIT) economists ${ }^{7}$. Yet this has not avoided "tribal" answers from salt or freshwater economists. Worse yet, both tribes share what Lo (2009) calls "physics envy" over organic analogies which would seem to be more appropriate to model the adaptive nature of individual and collective behavior but have remained far from the mainstream ${ }^{8}$.

Perhaps the way to go about it is to recognize at least another tribe. I call it the tribe of turgid economists, broadening the label "turgid" Carlos Diaz Alejandro used to describe the economics of Unequal Exchange in his Yale graduate course thirty years ago (Emmanuel 1969) ${ }^{9}$. In fact, the only methodological debate I remember, in part because I

\footnotetext{
${ }^{7}$ The profession needs humility he said, and added "anyone who thinks otherwise is an idiot." The 2009 awards testify that economics as a social science deals with institutional and governance issues Mocking rational expectations in a cartoon inspired by Voltaire's Candide appeared in the FT of 30 and 31 December: http://www.ft.com/cms/s/0/e5a1261c-f493-11de-9cba-00144feab49a.html.

${ }^{8}$ The British Academy Forum planned on this point took place at end 2009 and led to the second letter to the Queen mentioned in the text. There was another letter to the Queen written by "ten leading British Economists (...), claiming that the training of economists is too narrow: "Mathematical technique should not dominate real-world substance." (Hodgson 2009a). The letter came to my attention through João Rodrigues, a Ph.D. candidate at the University of Manchester. I subsequently learned that a web petition titled "Revitalizing Economics After the Crash" was organized by Hodgson (2009b) in support of Krugman (2009): "I think this is an important opportunity to make an impact, and I'd like to encourage you to add your signature. It's not an attempt to lionize Krugman (although he deserves full credit), but to use his forceful words to help reform economics. It's free and takes less than a minute of your time". The points in the letter to the Queen apply to the UK and maybe the US, but they do not reflect other perspectives: "The candor with which we dissect the lessons of the events of the past year and apply them in future will determine whether this salutary shock will turn out to have been a beneficial one". Clive Cookson, Gillian Tett and Chris Cook report on "organic mechanics" work, including Lo (2009), Haldane (2009) and others in the FT of 27 November. See note 20 and below in the text.

${ }^{9}$ Jedlicki (2007) has a summary. I applied this label when introducing in late 2009 the Portuguese edition of The Black Holes in Economic Science by Jacques Sapir (who, like Emmanuel, was a student of Charles Bettelheim's), ten years after the French original. The timing was good because of the revival of methodological quarrels in economics. These were disappearing around the time Harry Johnson visited Yale from Chicago and LSE. References abound for the ongoing debate: Financial Times editorial 27 July
} 
used it in my introductory macro course at Universidade Nova de Lisboa, happened in Slate Magazine in the Fall of 1996 launched by Paul Krugman's "Economic Culture Wars" following a critical review of his celebrated $(1995)^{10}$.

Figures 1 and 2 here

Two pictures illustrate respectively the origin of the crisis in the US economy and its effects on domestic output. Figure 1 (from Gjerstadt and Smith, 2009) could certainly motivate the Queen's question. In 2001, after four years of inflation-adjusted house price increases of 7,2\%, the Federal funds rate began a descent to its lowest recorded level reached in 2004. Krugman's blog (The New York Times 18 September) calculates the costs of the crisis for the US: compared with 2007 4th quarter, 2009 2nd quarter GDP was at 96 whereas it would be at 104 on previous trend. The 8 point fall, apparent in Figure 2 (from Menzie Chinn's econbrowser blog), is accompanied by an equally unusual 6 point decline in consumption and an unemployment rate close to $10 \%$. The graphs illustrate how large the issue is: the parallel with the 1920s - when residential mortgage rose from $10 \%$ of household net wealth to $29 \%$ - is striking. The recession which began end 2007 is about half of the Great Depression in the US - but worldwide it is the same as demonstrated by Eichengreen and O'Rourke (2009) in the most quoted Vox EU post ${ }^{11}$.

The quote from Krugman in Hodgson (2009b) follows: "Few economists saw our current crisis coming, but this predictive failure was the least of the field's problems. More important was the profession's blindness to the very possibility of catastrophic failures in a market economy ... the economics profession went astray because economists, as a group, mistook beauty, clad in impressive-looking mathematics, for truth ... economists fell back in love with the old, idealized vision of an economy in which rational individuals interact in perfect markets, this time gussied up with fancy equations ... Unfortunately, this romanticized and sanitized vision of the economy led most economists to ignore all the things that can go wrong. They turned a blind eye to the limitations of human rationality that often lead to bubbles and busts; to the problems of institutions that run amok; to the imperfections of markets - especially financial markets

(excerpted below in text), ft.com/arena "what is the point of economists" (Robert Skidelsky, calling for the reconstruction of economics as a moral not a natural science on 6 August; Samuel Brittan, comparing economists to the "Titanic designers" on 7 August); The Economist, 16 July ("macro and financial economists helped cause the crisis, failed to spot it and have no idea on how to fix it", contra Robert Lucas, "In defense of the dismal science", 6 August); NYT Magazine 2 September (Paul Krugman, "Why did economists get it so wrong?").

${ }^{10}$ Kuttner (1996), Krugman (1996), Galbraith (1996). Galbraith has also responded to Krugman's NYT Magazine piece. Both were at Yale when I was there in the late 1970s. Their latest debate follows below in the text.

${ }^{11}$ Available at http://www.voxeu.org/index.php?q=node/3421 with data comparing two world depressions with respect to Industrial Production, Stock Markets and Foreign Trade as well as the moentary and fiscal policy responses. Quoting http://krugman.blogs.nytimes.com/2009/03/20/the-great-recession-versus-thegreat-depression/: "Reading about the global manufacturing plunge, I wondered: how does the current slump stack up against the early stages of the Great Depression? The US has consistent industrial production data back to 1919, so it's a fairly straightforward exercise. At first, the current recession didn't hit industrial production all that hard. But the pace accelerated dramatically last fall, so that at this point we're sort of experiencing half a Great Depression. That's pretty bad". 
- that can cause the economy's operating system to undergo sudden, unpredictable crashes; and to the dangers created when regulators don't believe in regulation. ... When it comes to the all-too-human problem of recessions and depressions, economists need to abandon the neat but wrong solution of assuming that everyone is rational and markets work perfectly."

Galbraith (2010) begins with another quote from Krugman (2009): "Of course, there were exceptions to these trends: a few economists challenged the assumption of rational behavior, questioned the belief that financial markets can be trusted and pointed to the long history of financial crises that had devastating economic consequences. But they were swimming against the tide, unable to make much headway against a pervasive and, in retrospect, foolish complacency" and takes issue with him for not naming the exceptions: "Apart from one other half-sentence, and three passing mentions of one person, it's the only discussion-the one mention in the entire essay- of those economists who got it right. They are not named. Their work is not cited. Their story remains untold. Despite having been right on the greatest economic question of a generation - they are unpersons in the tale". He goes on to compare the distinction between saltwater and freshwater economists to Tweedledum and Tweedledee and concludes: "This remains the essential problem. As I have documented-and only in part - there is a considerable, rich, promising body of economics, theory and evidence, entirely suited to the study of the real economy and its enormous problems. This work is significant in ways in which the entire corpus of mainstream economics-including recent fashions like the new "behavioral economics" - simply is not. But where is it inside the economics profession? Essentially, nowhere. It is therefore pointless to continue with conversations centered on the conventional economics. The urgent need is instead to expand the academic space and the public visibility of ongoing work that is of actual value when faced with the many deep problems of economic life in our time. It is to make possible careers in those areas, and for people with those perspectives, that have been proven worthy by events. This is-obviously-not a matter to be entrusted to the economics departments themselves. It is an imperative, instead, for university administrators, for funding agencies, for foundations, and for students and perhaps their parents. The point is not to argue endlessly with Tweedledum and Tweedledee. The point is to move past them toward the garden that must be out there, that in fact is out there, somewhere" (emphasis in original).

While revisiting these economic culture wars more than ten years after helps deconstruct the letters to the Queen, the development dimension remains as implicit as the hypothetical exchange with President Lula mentioned at the outset. The "silo curse" brings out historical comparisons but also a broader geographical domain, beyond the "blue-eyed" or Western world. In other words, the dangers of "group think", apparent before this crisis, have not been analyzed in connection with global, or even regional, governance $^{12}$. Section 2 looks at how the G\&G interaction changes along the

\footnotetext{
12 In December 2006 (Franco, 2008, p. 235), Krugman spoke in Lisbon of "incestuous suppression" in connection with resistance to social security reform in the US. On healthcare he added: "The US is probably spending about three times as much per capita now as Portugal, with worse results in infant mortality and not much difference in life expectancy. The range of things that can be talked about in a
} 
development path and refers to organizational economics perspectives by Besley and Persson (2009) with respect to the origins of state capacity and by Garicano and Posner (2005) with respect from intelligence failures in the United States following the 9/11 attacks ${ }^{13}$. Guarding against simple solutions with respect to intelligence, they argue that decentralization reduces herding and sharing and that less centralized organizations adapt less well to a changing environment. On the positive side, they note that all organizations enable the constraints of bounded rationality to be circumvented, so that more information (e.g., intelligence data) can be gathered and a greater variety of expertise can be used in its compilation and evaluation than any individual or small group could achieve.

The conclusions of Garicano and Posner (2005) illustrate the nature of the approach. An organizational hierarchy enables the aggregation of information: a bit of information from the field is, if routine, dealt with by a field officer; if the bit is unusual, it goes up the organizational ladder to a more knowledgeable officer who decides what action to take; information that is truly exceptional continues up to the top of the hierarchy. This "management by exception" allows for the optimal matching of problems with expertise. Organizational problems arise in the three main steps in the process of generating intelligence: in reverse order they are intelligence analysis, intelligence sharing, and intelligence collection. A serious organizational failure at the analysis stage is "herding," or, as observers often put it, "group think," in which the accumulated information and conclusions develop such a strong momentum that they cannot be successfully challenged. Intelligence analysis succumbed to "herding" in the virtually unanimous conclusion of the intelligence community that Iraq had weapons of mass destruction. An erroneous consensus of this kind may be due to organizational malfunctions, such as a poorly designed information and communication structure or a bad set of incentives for agents. It also may be the unavoidable result of efficient but second-best design decisions. When a pattern is missed because different pieces of information are not shared, erroneous conclusions can result ${ }^{14}$. "Group think" may also be the result of an efficient organizational-design decision: the organization may be rationally designed to filter out most information on the way to the top of the organizational hierarchy in order

proper debate turns out to be limited, because there are people who are persistent participants in that debate, and exercise censure on themselves."

${ }^{13}$ As mentioned above in the text, the Queen's question was addressed to Garicano while Besley wrote the letters of the British Academy. Garicano and Posner (2005) take an organizational economics perspective on high level investigative commissions and the belief that Saddam Hussein had retained weapons of mass destruction.

${ }^{14}$ The authors add that this was a major factor in the failure to anticipate the 9/11 attacks. An organization can be poorly designed to achieve a desired goal. The Federal Bureau of Investigation is supposed to both solve crimes and conduct domestic national-security intelligence, but it is designed for the former task, and because the organizational structures required for the two tasks are different, it does not perform the latter task well. Two caveats are in order. First, while organizational problems may have contributed to the recent intelligence failures, nonorganizational problems, such as incompetence of individuals, political pressures, and sheer bad luck (intelligence has a built-in failure rate because it is an endeavor to uncover secret information), may have been larger contributory factors. Second, organizational reform is likely to have only limited efficacy even addressed to genuine organizational problems because of unavoidable tradeoffs. Nevertheless, they see the combination of criminal investigation and national-security intelligence as a clear example of combining incompatible missions in the same organization. 
to economize on the time and attention of senior management. In an organization that contains multiple layers of hierarchy in which experienced supervisors review information, ideas, and judgments coming to them from lower levels in the organization: fewer mistakes are committed that result from accepting bad ideas or judgments, but at the cost of mistakenly failing to act on sound ideas. Looser, less centralized organizations filter out fewer ideas and thus produce a more diverse set of options for the leaders of the organization to choose among. Which type of mistake is more harmful depends primarily on the organization's environment (Sah and Stiglitz, 1986). When the environment is unstable, the organization should be decentralized in order to maximize the likelihood that many fresh new ideas will be produced, for that will make it easier for the organization to adapt to a changing environment ${ }^{15}$.

\subsection{Nine points and then three more}

The nine points in the July 2009 letter follow, then the editorial and additional commentary before the additional points in the February 2010 letter.

\section{Ferocity not foreseen, powers not available}

Many people did foresee the crisis. However, the exact form that it would take and the timing of its onset and ferocity were foreseen by nobody. What matters in such circumstances is not just to predict the nature of the problem but also its timing. And there is also finding the will to act and being sure that authorities have as part of their powers the right instruments to bring to bear on the problem.

\section{Imbalances and risk neglected}

There were many warnings about imbalances in financial markets and in the global economy. For example, the Bank of International Settlements (BIS) expressed repeated concerns that risks did not seem to be properly reflected in financial markets. Risk management was considered an important part of financial markets. But the difficulty was seeing the risk to the system as a whole rather than to any specific financial instrument or loan. Risk calculations were most often confined to slices of financial activity, using some of the best mathematical minds. But they frequently lost sight of the bigger picture. Many were also concerned about imbalances in the global economy.

\section{Global savings glut and easy borrowing}

A period of unprecedented global expansion had seen many people in poor countries, particularly China and India, improving their living standards. But this prosperity had led to what is now known as the 'global savings glut'. This led to very low returns on safer long-term investments which, in turn, led many investors to seek higher returns at the expense of greater risk. The rise of China lowered the cost of many goods that we buy.

\footnotetext{
15 Garicano and Posner (2005) add two corporate examples: 3M provides its employees with ample discretion. It has a culture of forgiving failure and allowing individuals to buck senior management in pursuit of what may look like unrealizable ideas. When the environment changes slowly, so that adaptation is achievable by incremental adjustments, the organization should be designed with many filters so that the errors that are made are of the type "a few good ideas were not tried out" rather than "we went ahead with some terrible ideas and damaged our franchise." At Procter and Gamble, new product proposals go through 40 to 50 revisions until they reach the CEO for a decision.
} 
Through ready access to capital in the financial system, it was easy for households and businesses to borrow. This in turn fuelled the increase in house prices.

\section{Wishful thinking combined with hubris about risk}

There were many who warned of the dangers of this. But against those who warned, most were convinced that banks knew what they were doing. They believed that the financial wizards had found new and clever ways of managing risks. Indeed, some claimed to have so dispersed them through an array of novel financial instruments that they had virtually removed them. It is difficult to recall a greater example of wishful thinking combined with hubris.

\section{Politicians believed bankers were engineers}

There was a firm belief, too, that financial markets had changed. And politicians of all types were charmed by the market. These views were abetted by financial and economic models that were good at predicting the short-term and small risks, but few were equipped to say what would happen when things went wrong as they have. People trusted the banks whose boards and senior executives were packed with globally recruited talent and their non-executive directors included those with proven track records in public life. Nobody wanted to believe that their judgment could be faulty or that they were unable competently to scrutinize the risks in the organizations that they managed. A generation of bankers and financiers deceived themselves and those who thought that they were the pace-making engineers of advanced economies.

\section{Feel good factor led to delusion}

All this exposed the difficulties of slowing the progression of such developments in the presence of a general 'feel-good' factor. Households benefited from low unemployment, cheap consumer goods and ready credit. Businesses benefited from lower borrowing costs. Bankers were earning bumper bonuses and expanding their business around the world. The government benefited from high tax revenues enabling them to increase public spending on schools and hospitals. This was bound to create a psychology of denial. It was a cycle fuelled, in significant measure, not by virtue but by delusion.

\section{Lax regulation: don't do bubbles after dot.com}

Among the authorities charged with managing these risks, there were difficulties too. Some say that their job should have been 'to take away the punch bowl when the party was in full swing'. But that assumes that they had the instruments needed to do this. General pressure was for more lax regulation - a light touch. There was a broad consensus that it was better to deal with the aftermath of bubbles in stock markets and housing markets than to try to head them off in advance.

The experience after the turn of the millennium when a recession was more or less avoided after the 'dot com' bubble burst fuelled the view that we could bail out the economy after the event. Inflation remained low and created no warning sign of an economy that was overheating. But this meant that interest rates were low by historical standards. And some said that policy was therefore not sufficiently geared towards heading off the risks. Some countries did raise interest rates to 'lean against the wind'. 
But on the whole, the prevailing view was that monetary policy was best used to prevent inflation and not to control wider imbalances in the economy.

\section{Psychology of herding and no single authority}

So where was the problem? Everyone seemed to be doing their own job properly on its own merit. And according to standard measures of success, they were often doing it well.

The failure was to see how collectively this added up to a series of interconnected imbalances over which no single authority had jurisdiction. This, combined with the psychology of herding and the mantra of financial and policy gurus, lead to a dangerous recipe.

\section{Forecasting failure: never again?}

Individual risks may rightly have been viewed as small, but the risk to the system as a whole was vast. The failure to foresee the timing, extent and severity of the crisis and to head it off was principally a failure of the collective imagination of many bright people to understand the risks to the system as a whole. Given the forecasting failure at the heart of the question, government agencies might develop a new, shared horizon-scanning capability so that it never needs to be asked again.

The FT editorial "At your own risk" goes along the same lines as the letter. Excerpts follow (emphasis supplied): No economic theory can perform the feats its users have come to expect of it. Economics is unlikely ever to be very good at predicting the future. Too much of what happens in an economy depends on what people expect to happen. Even state-of-the-art forecasts are therefore better guides to the present mood than the future - though they may also be self-fulfilling prophecies. Dabbling in paradox limits the use of economics as a practical guide. Today the profession's best advice must convince politicians and the public to combat a crisis born of insufficient thrift by recourse to record borrowing. Those who saw danger had no easier task: even reminding people of gravity's existence is a hard sell when everything is going up. If predictions of physics-like precision are in demand, they will be supplied. Collective delusion must therefore be blamed as much on the consumers of economics - companies, investors, the media - as its producers. But its irresponsible use does not mean economics is useless. It is rather good at explaining the past and guessing unintended consequences of wellmeaning policies - invaluable tools for cleaning up financial markets. So we do need economists in public debate, but ones not blinded by mathematical sophistication or paradoxes beyond the lay public's grasp. The public intellectual's virtues - curiosity about other fields, aversion to dogma - could do the discipline much good. Unfortunately these are no longer much valued in the academic hierarchy.

The first letter to the Queen focuses on the advanced economies (especially US and UK) and only mentions China and India in connection with the "global savings glut" in point 3. Point 5 (seeing bankers as engineers) pertains more broadly to "advanced economies" and leads to the 'feel-good factor' there as creating a "psychology of denial" (point 6). The "pressure for more lax regulation" (point 7) was also greatest in US and UK since "some countries did raise interest rates" (point 7a) but the "psychology of herding" (point 8) fed the benign neglect about rising imbalances in the US balance of payments. The 
view of the US and China as a pseudo monetary union reinforced the complacency about systemic risks (point 9).

While the interaction between G\&G became unsustainable in UK and US in early 2007, the spread of the crisis to the eurozone and the Rest of the World (ROW) is conventionally dated with the failure of Lehmann Brothers in mid-September 2008 with trough in March 2009.

\section{Horizon-scanning is distinct from forecasting.}

When the challenge is about understanding discontinuities, effective horizon-scanning becomes necessary. It has both cultural and institutional components. There is a need to develop a culture of questioning in which no assumption is accepted without skepticism and a sufficiently broad array of outcomes is considered. But that comes to nothing unless the process is institutionalized within a body that pulls together these ideas and is responsible for drawing general lessons and concerns. This has not happened in the UK, where the Standing Committee staffed jointly by the Treasury, the Bank of England and the Financial Services Authority failed to spot risk coming down the track and act upon it. Moreover, without an institution to draw together intelligence across relevant institutions, there is no scope for a complete picture to be formed.

\section{Culture and institutions}

The best chance of avoiding the need to repeat the LSE question lies in quickening the sensitivities and states of mind of those charged with trying to anticipate what economic and financial shocks may occur in future. This can only happen where there is an environment which provides sufficient criticism of assumptions and is open to considering a wide range of possibilities. The hierarchical structures and histories of our many organizations provide a major challenge to making this work effectively. Hence the need for a combination of cultural and institutional reform.

\section{Government did not help}

It was often very hard to persuade the government to become properly involved in horizon-scanning. Some found it too gloomy; others saw the contingencies covered to be too remote. Sometimes involving Ministers in exercises related to horizon-scanning and the resultant contingency planning helped, but not all were keen to devote time to these. At the second forum of the British Academy, nobody volunteered either individually or institutionally to lead this task and there was skepticism about the ability to institutionalize such activity within government within current structures.

These three excerpts from the second letter underscore the "together alone " paradox within a single government more than the first letter but still neglect the international dimension of G\&G interaction, to which we now turn.

\section{HOW GLOBALIZATION \& GOVERNANCE INTERACT WITH CONVERGENCE}

\subsection{An interpretative framework}


The mutual relationship between globalization, governance and economic performance is described in Bonaglia et al. (2009) along the following lines: a nation's resource endowments and its productivity determine how fast it can grow and the level of its economic well-being in terms of income per capita, both in absolute terms and relative to the income frontier. Feed-backs are possible: a richer country growing fast may invest more resources in scientific research and technology development and thus enjoy higher productivity levels than a poorer, slow-growing economy. Through trade, capital flows or migration, globalization can influence the level of endowments available in an economy, or even, through international technology transfers, its productivity. Conversely a country's endowments of natural resources, labor, and capital, as well as its geographic location and efficiency of its production structures may determine how much it trades with the ROW in terms if goods, services and assets. Similarly, a country with good governance, namely a democratic state with high-quality institutions, effective corruption-free accountable bureaucracies, and a flourishing civil society may likely increase the quality, if not the quantity, of its most important endowment: its own people. Once more, cause and effect can be swapped: well-endowed countries may evolve towards democratic forms of government more easily, or, at least, they may afford investing more resources to build well-functioning institutions.

While these interactions have been at the core of economics, this has not been the case of "how G\&G interact with convergence", perhaps because of the interdisciplinary nature of globalization waves, of governance innovation and of the specific context in which the development process unfolds. Policy and institutional responses must necessarily change as the nature of globalization itself changes. Indeed, three successive waves of globalization (16th, 19th and 20th-21st centuries) have interacted with different forms of governance responses. $G \& G$ interaction is always defined by geography and history. In the current wave, the space and time context is captured by convergence to "best practices". Economic convergence is often measured as the income distance to the frontier represented by the most developed group of countries, often proxied by the United States, even though GDP per capita neglects income distribution and environmental sustainability and is more and more acknowledged as a poor measure of economic performance (Stiglitz, Sen and Fitoussi, 2009).

The quality of democracy is even more elusive: it is often measured in terms of electoral competition and political participation but best understood by its constituent political and economic elements. Political rights are associated with free and fair elections for the executive and legislative branches of power, freedom to constitute political parties, freedom of association, independence from political, religion and military authorities, real possibilities of the change of power and other related aspects of the political system. Key elements of civil liberties include freedom of thought, religion, association, free press and respect for the rights of minorities. The concept of economic freedom is more difficult to define as it may relate only to private ownership, prices being determined by market forces, de jure and de facto entry and exit, efficient rule of law and official economic regulation guaranteeing competition or also include the financial freedom brought about by currency convertibility, stability of money value, central bank independence and deep financial markets. Furthermore, the widely used indexes include 
low taxes, a small share of government spending in GDP and flexible labor markets, and this appears to some as too extensive a definition of economic freedom ${ }^{16}$.

Having reported results to the effect that trade openness reduces perceived corruption, Macedo (2001) claims that globalization improves governance in this way and emphasizes the role of expectations ("hope") in development. The results hold across levels of development and after correcting for the endogeneity of perceived corruption. Historical control variables (e.g. protestant tradition, de facto democracy and OECD membership) are also found to be highly significant. Eichengreen and Leblang (2006) found a two-way interaction between democracy and globalization over the entire 18702000 period $^{17}$. Similarly, in their analysis of the economic and political determinants of the state's capacity to raise revenue and support private markets, Besley and Persson (2009) refer to the historical evidence that financial development and openness co-varied over the last century. Yet, the different types of freedom interact differently with the trade and financial globalization variables over the period 1970-2004 and the results become more sensitive to regional context, and stages of national economic and institutional development.

Combining history with geography, comparable GDP data in 1990 international dollars adapted from the Penn World Tables and population from UN sources are available in the Total Economy Database and Angus Maddison websites over two millennia, at least for countries in the Eurasian landmass. While the data has been criticized, especially by Barro and Ursua (2008), it has become the benchmark for comparisons across time and space and, interestingly, originated in Marshall aid allocations through what became the OECD. Under the current wave of globalization, moreover, the risk of cooperation failures is not just international but it is greater among abstract regions where there is no peer review - that is, outside of OECD (labeled W for West). This leaves Africa plus South America (labeled S for South) and Asia (labeled E for East). Maddison treats founder OECD countries like Australia, New Zealand, Canada and the United States as Western offshoots and includes Turkey, together with Japan and Korea as well as the former Soviet Union in Asia. Thus measured, in year 1 the E region represented about $3 / 4$ of world GDP and population, W $15 \%$ and S $10 \%$, while W GDP per capita was already slightly higher than in the ROW.

In interpreting the evolution of the shares since year 1000 for GDP and population, presented in Figures 3 and 4 respectively, note that E population is always greater than $60 \%$ but that the GDP share dropped to around $20 \%$. S doubled its share of world GDP from 1820 to 1950 . Since then the share remained constant at around $10 \%$ with W roughly equal to $\mathrm{E}$. These shares are comparable to those prevailing in 1820 . Yet, in $1950, \mathrm{~W}$ accounted for $60 \%$ and $\mathrm{E}$ for $30 \%$. In terms of population $\mathrm{S}$ has more than doubled its world share from $10 \%$ in 1820 to $15 \%$ in 1950 to $22 \%$ in 2003 while E

\footnotetext{
${ }^{16}$ To enhance the quality of the democracy measure, Macedo et al. (2007a) look at the index of political rights and of civil liberties published by Freedom House and at the indexes of economic freedom published by the Fraser Institute and the Heritage Foundation.

${ }^{17}$ Macedo et al. (2007a) reestimated the model using a system approach and confirmed the two-way interaction but found that the effect of trade openness on democracy was insignificant.
} 
dropped from the original $3 / 4$ to $1 / 2$ and then rose again to $2 / 3$. In terms of GDP per capita, the changes in shares are magnified with shares relative to world average of $1 / 2$ for $S$ and over 2/3 for E. Again, since 1950, the share of $S$ remained around $10 \%$ but the pattern reversed almost completely between $\mathrm{E}$ and $\mathrm{W}$. The exclusion of $\mathrm{S}$ from income growth is evident, especially given the impressive reversal in world population shares with rising $S$ and falling $\mathrm{W}$.

Figures 3 and 4

Together with these insights, the Maddison database allows a "millennial" perspective on world regions and helps to avoid the pitfalls of a purely geographic approach: regions may be historical rather than geographical and interaction during the first wave of globalization (15th century) and even the second (19th century) did not involve nearly as many players as the current one. Yet the complementarity between globalization and regional integration and the development paradigm based on mutual accountability contained in the 2002 Monterrey declaration both suggest weak G\&G interaction in Sub Saharan Africa (SSA), in part because of lesser knowledge relative to other parts of $E$ and S. According to Maddison (2007), there are only estimates of GDP in year 1 for the five North African countries (Algeria, Egypt, Libya, Morocco and Tunisia). Estimates of GDP for Ghana and South Africa begin in 1820 and for the remaining SSA countries in 1950. The share of Africa in world GDP falls from over $4 \%$ to under 3\% in 1000, $1 \%$ in 1500 and around $.8 \%$ until 1820, when it begins to rise to about $1.2 \%$ in 1913. In 1950, when estimates for 34 new countries become available, the Africa share reaches under $4 \%$ again while SSA remains just under 3\%. Since then both shares have declined about $1 \mathrm{pp}$ of world GDP. As for the share of SSA in Africa, it rose from around 20\% until 34\% in 1913 and more than doubled to $3 / 4$ in 1950. Thereafter the SSA share in Africa GDP declined by more than $10 \mathrm{pp}$. The increase in population has been such that the relative stability in the share of world GDP implies a decline in GDP per capita of about 20 percentage points, from $42 \%$ of world GDP per capita in 1950 to $24 \%$ in 2003 . The corresponding figure for SSA is $18 \%$, forecast by IMF to rise to $21 \%$ in 2013 .

With respect to the relative strengths of the links between the current wave of globalization, the benchmark measure of freedoms and convergence, the empirical findings of Macedo et al (2007) reveal that political rights and civil liberties had a significant impact in the run-up to the third globalization while feedbacks were somewhat weaker. Further work is needed to understand the long-run dynamics and sustainability of this global system, in particular the mechanisms that could enforce or reinforce the expected positive effect of globalization on both convergence and freedoms. The particular interaction which involves democracy reflects historical, geographical, social, cultural, institutional and economic factors and the method employed focuses on the economic aspect of this relationship. Tavares and Wacziarg (2001) found trade-offs of a cultural nature in the interaction between democracy and growth: democracy brings additional pressure for current consumption, even to the extent of mortgaging future savings but it also leads to higher human capital, thereby promoting growth. A complementary explanation of the $G \& G$ interaction can be based on the manner in which diversity, be it socio-cultural, economic or religious, is addressed by a given society. 
In sum, allowing for the quality of democracy lowers the overall effect of globalization on democracy. One reason for this is the hypothesis that globalization's effects on democracy are mediated by slow-moving cultural values. This would imply that such variables might be accounted for by selecting groups of like-minded countries, like the OECD, for which the effect of globalization on freedoms would be stronger but this would neglect the convergence dimension, more visible on a global scale. The millennial perspective on world economic growth in $\mathrm{W}, \mathrm{E}$ and $\mathrm{S}$ illustrated this but there are as many significant differences within these broad regions as there are between them, depending on the purpose at hand. To extract information about dominant players by issue-areas it helps to focus on the economic dimension as measured by the level of GDP in the comparable units presented above.

\subsection{Diversity in G\&G interaction}

Previous waves of globalization did not involve as many players as the current one, and their relative positions have been changing fast, especially since the advent of the BRICs $^{18}$. Following the concept of interdependence in Cooper (1964) and Keohane and Nye (1977, 2000), Nye (2002) suggested a chessboard with three levels, security, diplomacy (intergovernmental cooperation) and civil society (transnational relations among private actors) to conclude that US maintained dominance on security relations was accompanied by a relative decline in diplomatic and private relations. While the relevant dominance dimensions lead to a matrix with four rather than three columns, we label it the Nye matrix. Aside from the military dimension, finance and trade would seem necessary but not sufficient because of the importance of factor endowments (land for short) as a cause of the international trade in goods and services which underlies most relations on the diplomatic and private level. Thus the dominance matrix in table 1 divides world GDP in 2006 into four quarters, arranged in decreasing order of response capability:

- North America (US, Canada, Mexico, labeled NA);

- European Union, labeled EU;

- Association of South East Asian Nations plus China, Korea and Japan, the socalled Chang Mai initiative, labeled EA (East Asia).

Table 1

ROW accounts for $1 / 4$ of world GDP and $1 / 2$ of the world population, including significant nations (Brazil, Russia, India, the other three BRICs) and salient regions (Africa and the Middle East, where most of around 70 "fragile states" are located). The four columns of the dominance matrix on issues of defense, finance, trade and land, i.e. endowments both

\footnotetext{
${ }^{18}$ From 17 to 29 January, a series of articles appeared in the FT celebrating this acronym introduced in 2001 by Jim O'Neill and popularized in the celebrated car race with the G-7 (Goldmann Sachs 2003). The idea was to embed the so-called China problem with India as the world's largest democracy, Russia, who joined the G-7 in 1998 seven years after the dissolution of the Soviet Union and its "second world" and Brazil who still seemed distant but reassuring. A box explained why South Africa did not quite make the grade but should be watched together with the large ASEAN member states and those who had joined OECD, such as Korea and Mexico. The BRICSAM project at CIGI reflects the larger list, which became the G-20.
} 
for agricultural and raw materials, illustrate the dominance of NA, EU, EA plus ROW. The US dominates the first two, even though in finance the creation of the euro in 1999 may lead to a shared dominance with the dollar. The new development is that the members of the Chang Mai initiative trade more with NA and EU than each side of the Atlantic trades with the other. Nevertheless, the fourth quarter of world GDP remains the most endowed in people, land and raw materials so that ROW cannot be seen as a residual of East and South. Taking a global (rather than a regional or national) view suggests the importance of governance innovation, but not enough is known about building global coalitions for change given that dominant players generate free rider problems and this prevents international cooperation. The "together alone" paradox stems from the inability or willingness of dominant players to foster international governance innovation.

Under growing financial globalization, the commitment of authorities who seek exchange rate stability through the adoption of fixed but adjustable parities is likely to be tested. As discussed in section 5 below, the debate about the appropriate exchange rate regime under financial market integration is sometimes described as "don't fix don't float" to the extent that both polar cases have their difficulties. One way of organizing the debate is the portfolio balance model of exchange rate determination, according to which volatility is scaled by the ratio of trade to finance (Kouri 1983). This insight has been applied to the international adjustment process by Kouri and Macedo (1978), Krugman (1983), Blanchard et al (2005) and it is helpful in understanding global imbalances, especially between the US and China. The argument that, under a fixed exchange rate between the renminbi and the dollar, China becomes a periphery of the US has been made by Dooley at al (2005). It is based on the persistence of effective capital controls between the two currency areas and on perfect substitutability between euro and dollar denominated $\operatorname{assets}^{19}$.

Data from Cohen-Setton and Pisani-Ferry (2007) is used to compute the Kouri ratio in the three regions above, showing that the trade dominance of East Asia does not carry over to financial issues. External financial assets and liabilities are about 8 times the annual trade flows in 2006 but only 3 in EA (table 2$)^{20}$. To the extent that regions are historical rather than geographical, it is easier to interpret EU, or even NA, than EA and the same can be said about $\mathrm{W}$ relative to $\mathrm{E}$ and $\mathrm{S}$.

\section{Table 2}

As mentioned in the previous section, the crisis originated in advanced economies (especially US and UK) and Asia is mentioned in connection with the rising deficit in the US balance of payments. Indeed the complacency about systemic risks is associated with the Bretton Woods II view of the US as an importer of last resort. It is there that the

\footnotetext{
${ }^{19}$ In addition to the portfolio balance argument mentioned above in the text, financial globalization erodes capital controls. The complacency about these global imbalances associated to so called Bretton Woods II view advocated by Dooley et al (2005).

${ }^{20}$ There is no data comparable to the table presented by Cohen-Setton and Pisani-Ferry (2007) but Haldane (2009) provides references to work carried out at the Bank of England.
} 
interaction between G\&G turned negative, spreading to the UK in early in 2007. Yet the impact on the eurozone and the ROW took an additional year, in part because the US recession of late 2007 was not immediately recognized. Successive bailout programs on both sides of the Atlantic were conducted in an haphazard and incoherent manner in the face of financial panic. They were accompanied or followed by stimulus packages. This was surprising given the strong financial links across the North Atlantic but reflect fault lines in national and regional financial supervision. The recapitalization of banks using taxpayer's money was finally agreed by the UK and adapted to the eurozone but the different systems of financial supervision continue to prevent a common position in the EU. This is not an issue of monetary policy but rather of information sharing about systemic actors, part of the macroprudential framework called for by the BIS (mentioned in point 2 of the July 2009 letter to the Queen). The German model prevents central banks from acting as lenders of last resort because using taxpayer's money might compromise their independence. Central banks are closest to commercial banks and other financial intermediaries, yet, more than two years after the crisis, the ECB does not have information on the systemic banks in the eurozone! This is particularly serious because, even before the tensions in the most indebted countries in the eurozone began to reverse the strengthening of the euro-dollar rate in late 2009, attacks on weak currencies were being replaced by attacks on suspicious balance sheets: nothing in left is right and nothing in right is left.

The surprise of the global crisis, recognized in both letters to the Queen but UK institutions were more severely judged in the second than in the first. Similarly, the blame on the economics profession - which has become more and more explicit since the fall of Lehmann Brothers - is muted in the letters of the British Academy. As documented in the previous section, the role of expectations as guide to the effectiveness of policy has been revisited, in ways that discard fully rational, expectations ${ }^{21}$. Malhoney and Mulherin (2003) provide evidence on the speed and accuracy of price discovery by studying stock returns and trading volume surrounding the crash of the space shuttle Challenger. While the event was widely observed, it took several months for an esteemed panel to determine which of the mechanical components failed during the launch. By contrast, in the period immediately following the crash, securities trading in the four main shuttle contractors seemingly singled out the firm that manufactured the faulty component. Much of the price discovery occurred during a trading halt of the firm responsible for the faulty component but the authors are unable to detect the actual manner in which particular informed traders induced price discovery. Thus it cannot be concluded that prices fully reflect all available information, as claimed by the efficient market hypothesis and firmly believed until the current crisis. Instead, the adaptive market hypothesis put forth by Lo (2009) implies that individuals make mistake, learn and adapt and that competition drives

\footnotetext{
${ }^{21}$ The cartoon inspired by Voltaire's Candide is quoted in note 7 above and related work featured in FT of 27 November in note 6. The notion of "diverse diversification" attributed to Nicholas Beale of Sciteb, a London consultancy, and David Rand is evoked together with parallels from "medical epidemiology" featured in the work of Lo (2009: "the US should set up a capital markets safety board to manage systemic risk, modeled on America's National Transportation Safety Board" according to the FT), Haldane (2009: "the banking world could do with an equivalent of the WHO" according to the FT). Zoologist Robert May is quoted as saying "the more I hear about financial economics, the more I am struck by its similarity to ecology in the 1960s": talk about humility!
} 
adaptation and innovation. Just like there are "rational herds" instances abound of the wisdom and madness of crowds ${ }^{22}$.

The Nye matrix and the Kouri ratio pictured in tables 1 And 2 respectively are relevant explanatory devices for the global crisis, but this does not mean that the current crisis is essentially "different" from previous ones as emphasized by Reinhart and Rogoff (2009 and 2010). Diversity in G\&G interaction is evident in the data gathered in tables 3 and 4, taken from their book. The list of sovereign defaults shows the interaction between financial reputation and democracy in Europe over eight centuries. When political rights decrease the capacity to tax, countries become serial defaulters but they are also capable of graduating. In Table 4, the share of years in default since independence or 1800 is similar in Brazil and Spain while France stands out for the share in a banking crisis. The change from 1979 to 2008 in the credit rating from Institutional Investor shows similarities between Portugal and Spain.

Tables 3 and 4

The management of diversity as a determinant of G\&G interaction in the Portuguese case is described in Macedo and Pereira (2007) and Macedo et al. (2009a) essentially by gathering insights from economists and historians. For example, the departure of the Crown to Brazil in 1807 just before the arrival of French troops and the liberal revolution of the 1820s influenced the transition of Brazil from empire to republic in 1890, while the successive revolutions in 1910, 1918, 1926 and 1974 certainly influenced the independence of the five African territories and their own very diverse experience with political and economic freedom. In particular, the presumption that political freedom is incompatible with financial instead of complementary damaged financial reputation considerably, as shown in Table 3 above. While one bankruptcy is recorded from 1300 until 1812 (against 7 in Spain and 9 in France), six are recorded until 1890 (against 7 in Spain and zero in France and Brazil). The experience with IMF adjustment programs in the 1970s and 1980s may also be relevant to understand how countries like Cape Verde and Mozambique considered financial reputation, as detailed in Macedo et al (2007) and Macedo and Pereira (2009). Unfortunately, the lessons seem to be forgotten in Portugal and this is making the budgetary situation more vulnerable to changing market sentiment about the eurozone as discussed in the section 4.2 below.

Besley and Persson (2009) look at how do risks of violent conflict affect the incentives to invest in state building, whether it matters that conflicts are external or internal to the state, when large states are associated with higher income levels and growth rates than small states and what relations to expect between resource rents, civil wars and economic development. About the origins of state capacity, they show that taxation and financial development are both positively correlated with income across countries and that causation runs from income to market support and taxation, not the other way around.

\footnotetext{
${ }^{22}$ Cooperative governance schemes like the first two G-20 summits did not manage to revive bank credit in part because banks feared fire sales and consequently did not want to sell troubled assets (Diamond and Rajan, 2009). The way in which evolution determines market dynamics becomes specific to the institutional and organizational setup.
} 
This is consistent with the argument that financial development is positively correlated with openness to international trade, as the latter expands the returns to reallocating capital. Investment in state capacity is declining in the share of resource rents in GDP because only produced output is taxed and legal capacity is only useful for produced output. War is important not only for building fiscal, but also legal capacity. While external defense is a natural example, the result applies to any national common-interest program, such as a universal welfare state or health program. Indeed, if the demand for public goods is expected to be high, any group that is in power has a greater incentive to invest in fiscal capacity to finance future common-interest spending. The incumbent group faces a smaller risk of the opposition using a larger fiscal capacity to redistribute against the incumbent. The effect of instability is larger in countries with less representative political systems. Conversely, the effect of political stability on economic institutions was particularly large in England after the Glorious Revolution. During a parliament dominated by the Whigs for more than 40 years, tax income rose to $20 \%$ of GDP, and institutions for charging excise and indirect taxes were put in place. In the second half of the 18th century, continued state capacity building by the dominant British elite culminated in the launch of an income tax during the Napoleonic wars, when the government raised taxes equal to a remarkable $36 \%$ of GDP.

\subsection{Culture and development goals}

Developed countries stand to gain from contributing, bilaterally and multilaterally, to policies that turn developing countries into more open economies, better integrated in the world economy. But globalization can only bring lasting benefits if the governance response is appropriate and diverse $G \& G$ interactions make it harder to find what such response might be. In particular, trust between local and foreign partners is even more crucial in developing countries, where most of the population is in a situation of absolute poverty and the state depends on external assistance because it is virtually devoid of a working tax administration. Even in the absence of armed conflict in the country or surrounding region, trust between all the partners and entities that finance development must rest on MDGs and on policies that sustain economic growth. The prerequisite of institutional change required by such policies confirms the importance of cultural factors. Culture affects such personal traits honesty, thrift, willingness to work hard and openness to strangers, in one word, trust. The example that is very clear here is the role of the family. Institutions such as the family are very different in different parts of the world and as mentioned below this has a well defined impact on economic development. A related example is sharing, which is part of Africa's cultural inheritance. Along these lines, the Monterrey declaration favors public-private partnerships for development, an examples are given below.

With respect to the religious dimension of culture, Barro and McCleary (2003) find a complex pattern of interaction, where the effect depends on the extent of believing relative to belonging: for given church attendance (belonging), increases in some religious beliefs - notably heaven, hell and an afterlife - tend to increase economic growth. For given beliefs, on the other hand, increases in church attendance tend to reduce economic growth. The concern with morality and the theological foundation of culture has increased in the context of the global economic crisis, where, according to the 
latest encyclical letter, the love of truth has been abandoned in favor of a crude materialism. Benedict XVI urges that this crisis becomes "an opportunity for discernment, in which to shape a new vision for the future" The Pope attributes the crisis itself to badly managed and largely speculative financial dealing but he resists the current fashion of blaming all existing world problems on the market economy. There are two practical implications of "love in truth". First: Moral priorities of generosity go beyond rights and duties. Second: The common good extends the good of individuals who live in society. The worldwide diffusion of prosperity should not be held up by projects that are protectionist: more not less trade is needed. Institutional cooperation is needed outside the usual players: the defense of multilateralism goes hand in hand with the realization that structural insecurity generates anti productive attitudes wasteful of human resources. Thus human costs always include economic costs and economic dysfunctions always involve human costs ${ }^{23}$.

Culture as learning is reflected in the evolution of US female labor force participation over a century. In her Marshall Lecture at the European Economic Association meeting in Vienna, Raquel Fernandez discussed the epidemiological approach as a way to separate the effect of institutions and other traditional economic variables from culture. Controlling for a large variety of socio-economic indicators, Fernandez (2007) shows that (white) men whose mothers worked while they were growing up tend to be married to women who also work: a mother who works increases the probability that man's wife works from $39 \%$ to $71 \%$. Moreover men brought up by working mother either prefer women who work or are preferred by women who want to work (preference transmission). For children born 1930-35 (not for earlier cohorts), more women with children worked in states with higher mobilization rates and more men were brought up by working women, so that it became more attractive for married women to work in these states. Since development also involves the expansion of women's economic and political rights, then it implies declining fertility. To find out whether cross-country differences are driven by genetic or environmental (including culture) factors, she compares a health outcome (e.g. heart disease) for immigrants with that for natives and asks whether health outcomes converge. If they do, one can conclude that the environment caused it. However the converse is not true. Health outcomes may differ because economic/institutional factors or culture might play a quantitatively more important role than genetics in cross-country differences in an economic outcome (e.g. savings) ${ }^{24}$.

Rising income divergence within and between countries was once an inheritance of import-substituting industrialization and central planning but subsequent attempts at promoting convergence by raising the growth rate of poor countries over that of rich ones have rarely been sustained ${ }^{25}$. Maddison (2001) explains economic performance by

\footnotetext{
${ }^{23}$ According to Sirico (2009), followed in the text, Caritas in veritate is in the tradition of St Thomas Aquinas, Frédéric Bastiat, Willem Roepke and even Friedrich von Hayek.

${ }^{24}$ When she addresses the behavior of immigrants differentially affected by shocks (language, employment, etc.), Fernandez $(2007,2009)$ contrasts assimilation and selection.

${ }^{25}$ Sachs and Warner (1994) showed that the conditions for convergence could be summarized by property rights protection (i.e. good governance) and openness to international trade (i.e. globalization). Unfortunately, in their (1995), the governance variable was dropped so that the importance of G\&G
} 
conquest, international trade and investment and technological and institutional innovation, as captured by governance. Maddison (2007) demonstrates that development involves an increase in productive capacity and rising per capita incomes, rising life expectation from 1820 ( 24 years in 1000 and the rise was almost imperceptible until then): now the average infant can expect to survive 66 years and the projection for 2030 is over 70. His figures have largely determined the productivity levels used in accounting for the sources of growth. Using new data on human capital, Daniel Cohen shows in Macedo et al (2002) that there is not a unique factor behind the poverty of nations. Poor countries are "slightly" disadvantaged in each one of the factors behind prosperity. But the combination of these slight weaknesses results in huge income gaps. This is why he claims that more rather than less globalization would make positive G\&G interactions more widespread. Yet, the difficulties in measurement and interpretation of changes in cultural and governance variables should be kept in mind. For example, many of the available governance indicators are very arbitrary and their use could damage peer pressure instead of promoting it, in part because changes in these indicators are not easy to interpret (Arndt and Oman 2006). In addition to cultural diversity, then, unavailability of data and inadequate analysis thereof are reasons for available indicators to damage peer pressure instead of promoting it.

Looking at the origins of such governance response confirms these fears but does not suggest any superior alternative among advanced countries as well as in Africa; the absence of emerging markets at least until the G20 summits is rather the worry here. As detailed in the annex (which adapts the comparison of IMF, OECD and EU methods in Thygesen, 2002), international peer review began with the post-World War II Marshall plan and the creation of the European Payments Union. The Organization for European Economic Cooperation which administered Marshall Aid was replaced in 1961 by OECD, which has a Western membership except for Australia, Japan, Korea and New Zealand. OECD, known as the "rich man's club" because its Development Assistance Committee gathered virtually all official donors, has adapted its peer review methods to emerging markets on a voluntary basis, in what is called a "surveillance" of nonmembers. Nevertheless, it stands for the polar opposite to Africa, where incomes per capita are among the lowest in the world, they share a call for better governance through peer review. Thus attempts at promoting mutual knowledge in Africa reflect the establishment of the African Peer Review Mechanism in July 2002 and the fact that 29 countries signed up. The acceleration of reports is evident: 5 countries were examined until 2007, 4 in 2008 and 6 expected for 2009 (more in African Economic Outlook 2009, p. 75).

Before the creation of AU, parallels of NEPAD with the Bretton Woods institutions or with the Marshall plan were made by African leaders. Indeed, the UN system, the IMF, the World Bank and the WTO collaborated, for the first time, in the process leading to the conference in Monterrey, Mexico in 2002. The Monterrey declaration, dubbed the Washington consensus "with a sombrero", was not implemented and the same can be said about the NEPAD as a continental initiative. Worse yet, sub-regional groupings such as

interaction was lost. Another caveat to ususal convergence measures is the exclusive focus on GDP growth, which is criticized by Stiglitz et al (2009), known as the report of the "Happiness Commission". 
the Southern Africa Development Community, which come under the rubric "SouthSouth co-operation", did not thrive either. The same can be said about traditional postcolonial organizations such as the Commonwealth or the Organisation Mondiale pour la Francophonie as well as multi-regional bodies (such as SEGIB the Secretariat for IberoAmerican Co-operation based in Madrid or CPLP), where the weight of the "North" relative to the "South" is smaller than in their English- or French-speaking counterparts. Nevertheless, OECD peer reviews have already been carried out for non-members. They could certainly be adapted to economic co-operation and development among groups of non-member countries, from regional ones to others based on some perceived cultural or linguistic trait. The idea of a club as a set of like-minded people carries over to that of a group of like minded countries whose commitment to democracy, market economy and world development is reinforced by mutually agreed procedures for policy review and evaluation. The success of the Marshall plan reflects this fact: a reform process can only be sustained when culture is used as a vehicle for change rather than against it. Even though deep differences in political and social cultures remain and may even widen under the threat of international terrorism, economic cultures have been converging and democracy has spread well beyond the OECD membership.

Progress toward reaching the MDGs continues therefore to face two major governance obstacles. First, international organizations do not seem able to work together. Second, the EU is the largest donor but its policies are not consistent across the 27 members, hindering visibility. These two obstacles reflect the difficulties of international governance innovation. Thus the G7 helped global governance in 1970s but lost initial impetus with gradual incorporation of Russia and the complexity of the enlargement to emerging markets of systemic importance, such as the BRICs. Morphing into G20 suggests momentum, but the September 2008 financial crisis and the existence of an informal group of finance ministers called the G20 explains that the perceived success of the three meetings at leaders level has been rather more on finance than on trade and development.

Policies for international reconstruction and development began with the Marshall plan and have been most effective in Asia, despite OECD's mostly European membership. This "reformers' club" has promoted the convergence in economic policy cultures and even in most other areas of non-military policies. Moreover, the discreet partnership launched in 2002 between NEPAD and OECD grew into the Africa Partnership Forum and the Paris declaration on aid effectiveness in 2005, which involved the stakeholders in the Monterrey process, including business associations, absent from the evaluation of the Comprehensive Development Framework described in World Bank (2003). This is different from the Washington consensus of 1990s because of the process of "mutual accountability" between donor and recipient. Thus the Paris declaration led to the Accra Agenda for Action (AAA), approved on the eve of the financial crisis. Even though it favored North-South-South cooperation, the AAA has encountered even greater obstacles in having donors deliver on their commitments. The entry into force of the Lisbon treaty in late 2009 has not simplified the European architecture for development cooperation. 
Before the crisis, the world was on track for halving poverty by 2015 (with a 1990 benchmark). Between 2000 and 2005: 120 million people out of poverty 2 million lives saved through reduced child mortality; 30 million additional 6-12 children going to school; 30 million additional families having access to drinking water; Boys and girls in equal numbers in primary school. Yet, global poverty progress was largely due to rapid growth in giant Asian countries: China, India, Indonesia and Vietnam. Most developing countries were projected not to meet most MDGs: although necessary, growth alone cannot do the job. Progress on MDGs is shaped by the global economic environment, by domestic policies and, for the poorest countries, how much and how well aid is delivered and used. Each one of these three factors looks worse with the global crisis. Tackling chronic poverty will remain a priority after 2015: MDG achievements will need to be sustained. This implies the need to consider MDGs as part of an overall sustainable development strategy ${ }^{26}$.

Based on its experience of economic integration, the EU can play a specific role in helping poor countries, especially in Sub-Saharan Africa, to reduce internal barriers to trade, correct market failures and increase regional ownership of reforms through peerreviewing. As Bourguignon et al (2008) acknowledged in their mid September report on MDGs, much needs to be done at the EU and its member states level to push this agenda forward. The deterioration due to the crisis has made it much harder to achieve policy coherence, particularly in trade, migration and development policies. Scaling up aid and delivering it more effectively is another major challenge in an environment where the EU seems to unable to bring about governance innovation - even though the complementarity between globalization and regional integration suggests positive G\&G interactions, with implications for freedoms and values. Positive interaction found between democracy and globalization remains when measures of political, social and economic freedom are used. The conclusion is that freedoms strongly interact with globalization, given income per capita, because the effect is mediated by slow-moving cultural values. Lack of state capacity is a major obstacle to development. In particular the capacity to govern causes growth and low capacity to tax is associated with low income. Causation runs from income to market support and taxation, not the other way around.

In other words, pro-poor growth illustrates a positive $G \& G$ interaction, whereas negative interaction hurts growth and development. Reaching the eight MDGs in 2015 presupposes sustained economic growth in addition to better governance and more aid, as recommended at the Monterrey Conference. The eighth goal (to develop a global partnership for development) reflects disappointment with the performance of developing countries which seemed to follow the policy recommendations of the so-called Washington consensus during the 1990s. As governance improvements were not commensurate with the challenges of globalization, especially in what concerns financial markets, some developing countries interrupted the long term convergence process even before the global crisis struck.

\footnotetext{
${ }^{26}$ Contzen (2010) quotes an estimate of DFID according to which the crisis delayed the progress to the MDGs by three years. No wonder that a workshop convened by DFID in Brussels June 2009 on what to do beyond 2015 conclude: restore growth!
} 
National capacity- and institution-building is decisive in developing countries because the private sector and civil society are less organised than the state, which even in fragile states remains a point of entry. The private sector and civil society are not only important from a national, regional and continental perspective but also from a local perspective, due to the proximity of business and of civil society to people's specific problems. The reason why the principle of proximity to various levels of government is fundamental in European integration doctrine, even if more flexible integration would make it more important in practice, as discussed in the next section. The local dimension is essential for the credibility of what the private sector may be able to do at national, regional and continental levels because collaboration with the state has to be assessed from the bottom up. In this context, public-private partnerships help bring about policies at the national, regional and global levels capable of promoting good governance and sustaining the reform process. The use of public-private partnerships in reconciling seemingly divergent interests between the public sector and private business can be extended to development areas because all parties gain from a concerted approach - but the existing institutions often discourage co-operation. To openly discuss what the interests of various stakeholders are and to seek a solution that best satisfies most interested parties is certainly preferable to imposing policies in exchange for official assistance.

Trust between social and economic partners, an environment favorable to business development, and better co-ordination between development finance institutions may all contribute to positive governance responses. As such, they also help translate the MDGs into national and global policy proposals as required by the eighth goal, which features targets for aid, trade and debt relief. In this context, public-private partnerships become an important instrument in creating an environment favorable to the normal functioning of business and the attraction of investment, an essential element in generating employment and creating wealth. To the extent that they broaden the knowledge base for policy dialogue between business and the public sector (points 24 and 25 of the Monterrey Declaration), public-private partnerships help to define the common good and the best ways to bring it about in each country.

The longer-term objective of public-private partnerships is to improve the environment for the domestic private sector and to build confidence and trust between partners, including the providers of finance for development. The concept is applicable to a wide range of countries wishing to respond to the challenges of good governance and to develop the private sector. Experience has shown that the transition tends to be rather slow from the usual adversarial relation between the public and private sectors to the desired partnership relationship in search of the common good and the best forms of attaining it.

Social dialogue has proven to be a successful investment in the progressive building of trust relationships between agents of the public and private sectors. For this to occur, the data and information that serves as a basis for such dialogue should be locally developed and not provided by external sources, so that the local public and private sectors can feel a sense of ownership of the information they use in their deliberations and decisions. The 
advantages of ownership do not override the need for the policies to have technical and economic merit. Only in this way will developing economies be able to attract the external public and private, bilateral and multilateral, resources that are indispensable for the national effort to be successful.

It is expected that public-private partnerships will lead to a closer and more effective communication between the public and private sectors. Experience shows that by participating jointly in working groups, seminars and conferences organized to discuss matters of common interest, both sectors gain a better appreciation of the concerns and interests of the other party. Over time, the initial defensive positions give way to a partnership between different agents concerned with achieving a common objective. Examples are innovative forms of financing that allow more firms to take advantage of positive prospects while smoothing the impact of bad times; or indicators of economic activity that all economic agents may utilize to assess cyclical perspectives. The aim is to facilitate dialogue between national agents and to provide locally produced economic information to foreign investors and other partners.

This broadening of the knowledge base will in turn promote the adaptive capacity of society as a whole, a key to fast growth. The success of any public-private partnership will naturally depend on the preparation and motivation of each party. The better organized and prepared is the private sector, the more easily it can take coherent positions and contribute positively to discussions and to decision taking. Similarly, a local private sector that is well-organized and technically competent can more easily be an effective partner to foreign investors, avoiding foreign capture of all good investment opportunities. The provision of technical assistance in the context of a public-private partnership can thus help private sector associations to mature or, at very least, to point out the major shortcomings and indicate where assistance could most profitably be applied. Business associations such as those gathered in the Business and Investment Advisory Committee of the OECD or initiatives such as the European Round Table of Industrialists have been active in promoting and disseminating comparisons of best practices in various aspects of corporate governance and investment climate. Yet these initiatives remain unusual in developing countries.

\section{5. CPLP and mutual knowledge}

Portugal and Brazil, five AU members (Angola, Cape Verde, Guinea-Bissau, Mozambique, São Tomé e Príncipe) and make up CPLP, with headquarters in Lisbon and under Portuguese presidency of its council in 2008-2010. Like Portugal as a tourist destination in the early 1970s, CPLP remains a "well kept secret" of culture-based multilateralism: "the mutual friendship among members" mentioned in the treaty is not enough to build a global partnership for development from the perspective of the group, what is called global lusofonia to underline that the concern goes beyond CPLP members. The contribution of Brazil was decisive in the creation of CPLP in 1996, the joint presidency of the secretariat and of the council in 2003/2004, and the creation of Business Council (CE) with a secretariat at ELO - Portuguese Association for Economic Development and Co-operation. The two more advanced members feared that an economic dimension would trigger expectations of larger development assistance towards 
PALOP (and Timor since 2000). Yet the Herfindahl number equivalent is 1,4 - the same as for NAFTA - and GDP shares of the four larger countries were never smaller than 99.75\%. The Bissau declaration aims at monitoring progress with respect to reaching MDGs. It emphasizes that the underlying philosophy is one of "genuine partnership for development", based on "mutual knowledge", an original concept which suggests governance innovation.

That the national and regional common good can be complementary has implications for the complementarity between regional and global surveillance noted in the Monterrey consensus. Another example is provided by the multi-regional CPLP: Portugal and Brazil, its two more developed members stand to gain from contributing to the integration of the other six in the world economic system. For example, in response to a proposal from Brazil, externally funded work on CPLP's poorest countries was added to the Development Centre's activities (OECD, 2003, p. 52) in 2000. Support of public private dialogue was the main purpose of a Mozambique pilot project and of its extension to other African countries, like the Democratic Republic of Congo, reinforcing coverage of the Southern Africa Development Community (Macedo, 2003). This was a first contribution to inserting CPLP in the quest for "mutual knowledge". The gains from joint actions with systemically significant emerging markets who were or became members of the Development Centre, such as India or South Africa, can be even greater if these actions enhance the South-South co-operation dimension without diluting the common cultural allegiance. In this regard the attendance at the first Ministerial Forum for Economic and Trade Cooperation between China and Portuguese-Speaking Countries in Macau in 2003 provided a good precedent for greater visibility of work carried out under OECD auspices. The presentation of OECD work convinced the national authorities present, especially the host country, that peer review mechanisms help improve the governance response to globalization and signal the rising financial reputation of emerging markets, thereby accelerating reforms and promoting the agenda of SouthSouth co-operation.

In accordance with a decision taken at the Maputo Summit in July 2000, the first CPLP Business Forum was held in Lisbon in June 2002 and decided to set up a CE, whose objectives were listed at the Brasilia Summit in July 2002. They were: (i) to enhance capacity building of business associations in member countries as well as to promote cooperation between them; (ii) to create a business network in the regions where lusophone enterprises operate; (iii) to encourage strategic partnerships; (iv) to promote innovative financing methods, and (v) to support local private sectors in the publicprivate dialogue. Progress towards meeting these objectives was reviewed at the second Business Forum, held in Fortaleza, Brazil in June 2003 after the Brazil-Africa Forum. At the Coimbra Ministerial meeting, it was also decided that the Business Council should begin operation in 2004 and the communiqué stated that CPLP Ministers welcomed the collaboration with OECD in the framework of NEPAD and encouraged further initiatives along the same lines. Similar encouragement was voiced with respect to UNESCO and the UN World Food Program, also represented at the ministerial. The message was that 
the various experiences with public-private partnerships have improved governance and mutual understanding between public and private partners ${ }^{27}$.

Facilitating North-South-South cooperation also provides a European identity in development co-operation which has been lacking even though the EU (including the Commission and member states) is the largest donor. Greater North-South-South partnership, as envisaged by the AAA may be easier in areas where mutual knowledge is greater. The Consultative Group on International Agricultural Research (CGIAR), housed at the World Bank, is the international body that sparked the "green revolution" in crop yields during the 1960s and 1970s which alleviated poverty throughout Asia. Due to a lack of support for implementation in Africa, the "green revolution" did not benefit the poor there. Symbolically, the first meeting of the CGIAR in Africa announced a major reform, implemented throughout 2009 and to be assessed at a stakeholders' conference in Montpellier, France planned for end March 2010 with the Global Forum on Agricultural $\operatorname{Research}^{28}$.

Contzen (2009) discusses the effect of the global crisis on the role of Science and Technology for Development and called for a further reinforcement of the knowledge base by capacity building in Science and Technology, using all forms of partnership, North-South-South, regional, public/private and for development of technological infrastructures, notably in Information and Communication Technologies. In addition, stimulating more local innovation which contributes to good capacity utilization can take place through four complementary approaches:

1. Giving more emphasis on innovation driven by local demand, notably the societal demand

2. Devoting more attention to organizational innovation adapted to local conditions

3. Reaping the benefits of new innovative developments, notably in the energy and environmental fields, arising from the stimulus packages of developed countries

4. Using the model of "non R\&D innovators" developed successfully in Europe (cloud computing, for ex.)

One reason why North-South-South co-operation may be the way to go is that questions arise about the effect of cultural and linguistic proximity on the effectiveness of peer pressure. If the Commonwealth had not been able to improve economic and political governance among its members, why would this happen in the CPLP group, whose Business Council was not even in operation yet? The fact that CPLP is much closer to South-South co-operation than the Commonwealth goes in the same direction, but after several years, CPLP and the Macao Forum have not managed to become complementary.

\footnotetext{
${ }^{27}$ The subsequent incorporation of NEPAD in the AU and the creation of the African Partnership Forum diluted this emerging partnership. Nevertheless, the OECD Development Center was reinforced after the entry of three other African countries (Egypt, Mauritius and Morocco).

${ }^{28}$. This will be preceded by a gathering of representatives of 36 universities and institutes in 19 European countries who founded an association and a European economic interest grouping whose name changed from ECART to AGRINATURA. Recent publications on development successes in agriculture are Spielman and Pandya-Lorch (2009) and Braun et al (2009).
} 
The Ministers of Science, Technology and Higher Education of CPLP gathered in Lisbon on 29 August 2009 called for common sets of indicators in their fields, along the lines of the declaration approved the year before - which recognizes that academics, policy makers, the business community and civil society face the common challenge of learning, through joint endeavors, to use scientific knowledge for sustainable development to improve human well-being, based on effective governance for inclusive economic globalization. It maintains that governance responses to globalization are more likely to promote sustained development if they are rooted in local cultures and that shared values are critical for fostering cooperation based on trust and mutual accountability. Coming back to initiatives of culture based multilateralism, the Lisbon declaration on science and technology for global development of 30 September, 2008 was approved at the workshop on Committing Science to Global Development convened on behalf of the CGIAR, the United Nations University and research institutions in CPLP ${ }^{29}$.

\section{REGIONAL GOVERNANCE AND FLEXIBLE EUROPEAN INTEGRATION}

\subsection{The exchange rate regime, fiscal rules and policy guidelines}

Regional governance is most advanced in Europe and includes various layers (eurozone, EU, candidates and neighbours in South and East, ACP partners). The commitment at the European Council of Spring 2000 of making Europe "the most dynamic and competitive knowledge-based economy in the world" by 2010 extended from EU15 to 27, even though structural indicators benchmarks included in the so-called Lisbon agenda were rebased at mid-term. At the request of the European Council of Spring 2004, reviewed in Spring 2005, the Kok report addressed the question of how to face the challenge of combining growth and employment in an enlarged union facing a competitive North America and $\mathrm{Asia}^{30}$.

As slippage in implementation continued the Lisbon agenda was formally abandoned by the first Barroso Commission and renamed 2020 by the second, after the entry into force of the so called Lisbon treaty. The painful process leading to institutional reform in 2009 lasted a whole decade including a convention on the future of Europe and the complex Constitutional treaty it approved which does not meet simple tests for separation of powers, as illustrated e.g. in The Federalist papers, and was rejected by voters even though it remains close to the Lisbon treaty which became effective on 1 December, 2009. The treaty contains a useful flexibility clause, which should promote governance innovation but has not managed to avoid the current sovereign debt turmoil in some eurozone countries.

The choice of the exchange rate regime has a regional dimension. Regional integration reinforces peer alignment, contributing to the atmosphere in which peer review and surveillance take place. The EU and Euro area policy review processes are very intensive,

\footnotetext{
${ }^{29}$ The workshop followed the ECART general assembly under IICT presidency and preceded the 15th meeting of the Executive Council of CGIAR held at IICT. This multistakeholder declaration was "leveraged" at a meeting convened by CPLP, IICT and the Ministry of Science and Technology of Mozambique, held at the margin of the CGIAR general assembly on 30 November. The declaration is available at http://www.mctes.pt/archive/doc/resolution.pdf

${ }^{30}$ European Council (2004). Recall the three quarters of world GDP accounted for by US, NA and EA in table 1 above.
} 
with peer pressure based on elements that cannot be replicated in any looser form of international institution. There are elaborate, frequent procedures sometimes based on rules, but mostly on national commitments to which it is the task of the monitoring agencies such as the European Commission, to keep countries to. The involvement of high-level officials is much greater than at the IMF or the OECD, so that the arrangements in place within the EU give by far the greatest scope for the exercise of peer pressure and supervision.

Currency crashes underscore the evidence that the combination of pegged exchange rates and open capital accounts are prone to costly accidents. In the 1990s, soft pegs and narrow bands $(2.25 \%$ in the European Monetary System) created a one-way bet for speculators, as convergence plays in connection with the EU southern enlargement were encouraged by pegs that assumedly minimized currency risk and thereby created investor moral hazard. The widening of the bands was thus a necessary step towards monetary unification. Mexico's 1994-95 highlighted the same crisis mechanism as slow disinflation in the presence of heavy intramarginal intervention to defend the crawling peg for the peso had created cumulative competitiveness problems and a large current account deficit financed by short-term bonds.

The initial gains in credibility brought about by hard pegs are often ephemeral, and the same is true of lower capital cost. Both francophone Africa and Argentina became trapped by an inappropriate anchor currency - inappropriate as the anchor did neither reflect their trade directions nor their cyclical needs. Thus the Franc zone peg amplified good and bad times while in Argentina a monetary panacea turned into fiscal straightjacket with high liquidity requirements. Intermediate regimes can stabilise real effective exchange rates of developing country groups but peg to single currency is exceptional. As there are few currencies available to borrow credibility from, to earn credibility demands a process of institutional development and economic flexibility rather than importing it through a hard peg and forgetting about domestic reforms. Both pure floating and hard pegs make future regional cooperation more difficult. This is important in a world of regional trade blocs which look for ways to intensify cooperation. A float is an inherently unstable regime for countries competing on world markets for a similar range of products and hence sets incentives for beggar-thy-neighbour competitive devaluation. Floating induces non-cooperative strategies, especially when the competing neighbours face a common shock. Hard pegs are hard because it is so difficult to reverse them and because they lack an exit strategy. They are thus only suited for countries which aim at joining a monetary union with the anchor currency in not too distant a future. Once again, the perspective of joining or creating a monetary union can make intermediate regimes more robust in the mean time. The complexity of basket pegs with bands hampers their verifiability, but is nevertheless needed for credibility. Once the effectiveness of the multilateral surveillance framework is verifiable, there should be greater tolerance for intermediate regimes. As a consequence, the argument that they are "too complicated for locals and for Wall Street" need not apply.

The way in which geographical peripheries can acquire global reputation is by setting up a multilateral surveillance framework, which is necessarily a group arrangement to 
overcome the cost of physical distance through financial proximity. Doctrinal controversies often reflect different assumptions about the relative importance of initial conditions, terminal conditions and the speed of adjustment also called capacity to transform $^{31}$. In developing economies, though, the institutional framework for such an orientation is lacking, so that the rules for monetary stability are not credible. Moreover credible surveillance is needed for geographical peripheries to acquire global reputation. The time it takes for a nation to acquire a reputation for financial probity varies but it typically involves several general elections where alternative views of society may confront each other. To construct a social consensus domestically, credible signals that the authorities are committed to reform may be needed. If stable democratic governments succeed in implementing reforms which help to achieve convergence between poorer and richer nations and regions, they can set off a self-reinforcing virtuous cycle of stability and growth. On the other hand, there will be a vicious cycle if short-lived governments, fearing the social conflicts associated with reforms, delay implementation and impair convergence.

Multilateral surveillance helped former EU peripheries earn credibility through the operation of a code of conduct built up over the years, which transformed the Exchange Rate Mechanism from an exchange rate arrangement into a convergence instrument. This code of conduct favoured a medium term orientation of macroeconomic policy, coupled with measures designed to improve the functioning of factor markets and of the public sector. Actually, "sustained regime change" was identified as a condition for benefits to accrue to peripheral nations or regions. This argument was especially strong under the limited labour mobility and flexibility, coupled with low fiscal redistribution among states, which prevails in the European economy. In these circumstances, exchange rate adjustments may become necessary to eliminate declines in competitiveness but they may not succeed in changing relative prices. The greater the underlying capital mobility and the more likely the repetition of exchange rate adjustments, the less effective a devaluation will be. This is consistent with survey data suggesting that firms did not expect devaluation to solve their problems but rather thought that credit constraints were a more severe hindrance to expansion at the peripheries than at the centre.

With high capital mobility, exchange rate stability requires a speedy real and nominal convergence process. The indicators of budgetary discipline have become signals of regime change sustained by the structural reform of the public sector. It is well known that financial markets tend to exaggerate rather than to dampen such signals, apparent reversions during a relatively rapid convergence are also more liable to misinterpretation. The cohesion objective involves a degree of social awareness that may not be required with respect to the convergence of fiscal variables. In any event, whatever the credibility of national policies, it was apparent even before 2008 that fast convergence is more

\footnotetext{
${ }^{31}$ The term is from Kindleberger's classic (1962). On initial and terminal conditions, Krugman (1991) showed that there are conditions under which the latter rather than the former are the key determinant of choice of equilibrium. The three environments in which an expectations-driven equilibrium exists boil down to a comparison between the rate of interest and increasing returns relative to adjustment costs, whereby faster economic adjustment helps prevent policy reversals for any given level of interdependence in time (discount rate) and in space (externalities).
} 
difficult with slower growth and that the main macroeconomic costs arise before the main microeconomic benefits are felt.

If, in the final analysis, the exchange rate reflects the credibility of national policies over the medium term, it may do so with considerable noise if the entire parity grid is under attack. This is why little indication about the credibility of national policy could be gathered from the realignments which occurred during the turbulent 1992-93 period. Speculative attacks on more vulnerable currency parities have more negative effects on the system if parities are already locked than if they continue to be flexible. Flexibility within a sufficiently wide band allows speculation not to be a one-way bet. When very wide bands of $15 \%$ replaced the normal fluctuation margins, the external discipline provided by the grid no longer obtained and each central bank could decide whether or not to intervene within the old fluctuation bands. Most decided to do just that, so that the convergence process was not hurt by the decision to widen the band. The lesson from the currency crises is that the largely unwritten code of conduct implied more effective coordination mechanisms among monetary and fiscal authorities than expected. Noncompliance with the code of conduct played a major role in the development of the currency turmoil, but the system regained stability after the widening of the fluctuation bands, which limited speculative pressure by eliminating one-way bets and reintroducing two-way risks.

The set of principles, rules and code of conduct which underlie the parity grid have proven correct for the single currency, so that the widening of the bands was a positive step towards the euro. When the decision to widen the bands was taken, however, many observers and prominent economists stated that the euro was dead, but the opposite was more likely. The best indicator of policy credibility is that multilateral surveillance is effective. It is the multilateral surveillance framework that determines the choice of an exchange rate regime.

In the run-up to the euro, there was a fear that restrictions on fiscal policy called for by the excessive deficit procedure contained in the Maastricht treaty and by the Stability and Growth Pact (SGP) would hurt growth and prosperity. Nevertheless, it has been shown that the retroactive application of the SGP would not have exacerbated recessions over the 1961-97 period. The first suspension, decided on November 2003 by the EU Council of Ministers, followed numerous prior suggestions that it should be scrapped, or amended to make it more effective, especially for large countries, whose deficits most threaten the stability of the eurozone. However, Buti, Eiffinger and Franco (2003) show that, against established criteria for an ideal fiscal rule, the design and compliance mechanisms fare reasonably well. Its weaknesses tend to reflect trade-offs typical of supranational arrangements $^{32}$. With the crisis, moreover, the timing of exit strategies from the stimulus

\footnotetext{
${ }^{32}$ The first suspension of the SGP illustrated the problem in the EU, but it is of course a danger for any international organization, as some countries have a much larger weight than others. Discussion on the possible breakup of the eurosystem carry the same message (Eurointelligence 2009) and has been exacerbated by the crisis in public finance in some of the member countries, notably Greece. This has been in part the consequence of the misreporting of data to Eurostat, in violation of a centralization principle included in the Maastricht treaty.
} 
packages has been constrained by suspicions about the ability of governments to repay their mounting public debts. This has been a greater problem for advanced countries because their public debts are larger. According to Reinhart and Rogoff (2010), when public debt reaches $90 \%$ of GDP, growth is impaired. In the eurozone, there is the additional problem of graduating countries such as Portugal or Greece (see table 4 above) whose financial reputation may not be established enough to avoid negative consequences of rumors of possible default (Krugman 2010).

While the suspension to avoid possible penalties makes future fiscal rules less credible, there is consensus on the need for such rules to enforce the Treaty's "no bail-out" provision. In fact, evidence from the markets suggests that the SGP has not hurt Euro credibility. Persaud and Metcalfe (2002) analyse the impact of over 400 news stories about breaches of the SGP on several measures of market credibility (changes in real yields, changes in real yield spreads to the US, changes in the yield curve, changes in the euro trade weighted exchange rate, positive correlation between eurozone equity and bond prices) and find that there is no effect. A finer analysis, reflecting the contents of the stories, allows them to conclude that the SGP alleviated concerns about "the free rider problem that potentially arises with the adoption of a common currency across a group of states with national budgets". They suggest that "an amendment that increased policy flexibility, but at the same time tightened fiscal discipline and its enforcement may be greeted positively",33.

If, under the current degree of EU fiscal integration, correcting excessive deficits is difficult for member countries, buttressing the soundness of public finances is a formidable task in countries with histories of high inflation, where neither the social partners nor public employees automatically appreciate the benefits of the regime change that the policymakers are attempting to engineer. Errors in policy appraisal can unduly raise the costs of reform, when information about the change in regime is not readily available to international financial markets. Repeated market tests of the authorities' commitment to exchange rate stability may result from this imperfect information. If these tests of the authorities' resolve greatly increase the cost of defending the exchange rate, they can lead to policy reversals. Conversely, if the volatility of the exchange rate is a direct consequence of system turbulence, market tests will be short-lived and the threat of a reversal will become less and less credible, both abroad and at home.

The Euro delivered convergence and cohesion in its first ten years because the new politics of credibility overcame financial hierarchy among sovereign risks. Trade unions recognised the perverse interaction between price and wage increases (which hurts the poor and unemployed disproportionately) and public opinion accepted the medium term stance of policy. Yet it took longer to convince voters than markets, and some countries used the Euro to procrastinate on their unpopular reforms, threatening the benefits of the stability culture with the "Euro hold up" (Buiter and Sibert 1997; Macedo et al 2001).

\footnotetext{
33 According to Buti, Eiffinger and Franco (2003), "redefining the medium term budgetary target, improving transparency, tackling the pro-cyclical fiscal bias in good times, moving towards non-partisan application of the rules and improving transparency in the data can achieve both stronger discipline and higher flexibility".
} 
While this tendency to procrastinate casts doubt on the efficacy of the European financial architecture perspective, more flexible integration schemes may lead initially reluctant states to join in and increase the reform momentum.

\section{2. Flexible integration in the $\mathbf{E U}$}

Since its meeting in Brussels in late 1993, the European Council has been issuing Broad Economic Policy Guidelines against which policy and performance in the member states are to be gauged in what has become a regular test of the multilateral surveillance framework for all EU member states. The progress of policy reform stands on how effective this framework might be among union officials whose interaction with national officials should be accountable in their respective parliaments and in the European parliament. This has been a dynamic process moving EU member countries' national policies towards integration leading to binding recommendations and sanctions. Until 2008, the EU used different surveillance processes for different policy areas and this surveillance instrument set out the general directions that economic policies should follow. The guidelines became a very detailed policy co-ordination instrument, including recommendations for structural policies, even though there was no way to ensure the coherence between among the different surveillance processes (SGP, Luxemburg process for social issues, Lisbon strategy, etc). This is why the Integrated Guidelines, adopted in Spring 2005, lay out a comprehensive strategy of macroeconomic, microeconomic and employment policies to redress Europe's weak growth performance and insufficient job creation, bringing together for the first time various guidelines in one single, comprehensive document. According to the European Commission website, this helped create more than $18 \mathrm{~m}$ new jobs before the financial and economic crisis hit. When the economy slumped, the EU acted to stabilize the financial system and adopted a recovery plan to boost demand and restore confidence. The plan is delivering a major fiscal stimulus, with measures to keep people in work and public investment in infrastructure, innovation, new skills for the workforce, energy efficiency and clean technologies to meet the goals of the Lisbon strategy. A new strategy dubbed EU 2020 strategy should enable the EU to make a full recovery from the crisis, and help speed up the move towards a greener, more sustainable, and more innovative economy (European Commission 2009).

These strategies can be expressed as $\mathrm{CI}(\mathrm{SR})^{2}<=\mathrm{CM}+\mathrm{OMC}$. In European jargon, this is a Comprehensive, Interdependent and Self Reinforcing Series of Reforms brought about by Community Method and Open Method of Coordination. In fact, more than a hundred indicators were associated with the Lisbon process, making this instrument ineffective for the Heads of State or Government and the wider public annual. Kok's suggestion was that the Commission should present updates on the key 14 Lisbon indicators in the format of league tables with rankings (1 to 25), praising good performance and castigating bad performance - naming, shaming and faming. This "name \& shame through league table" was accepted with the exception of the Heads of State or Government, who appoint a special representative (known as Mr or Ms Lisbon) to induce peer pressure and benchmarking and to facilitate exchange of best practice, making better use of the 14 indicators and better communicating the results in order to ratchet up the political consequences of non-delivery. The details of the structural indicators and targets are of 
interest because they show the interplay between structural and macroeconomic policy coordination. Five areas of policy were identified: the knowledge society, the internal market, the business climate, the labor market and environmental sustainability. On the knowledge society, the objective is to increase Europe's attractiveness for researchers and scientists, make Research \& Development a top priority and promote the use of information and communication technologies. On the internal market, complete the internal market for the free movement of goods and capital, urgent action to create a single market for services, improve the business climate, reduce the total administrative burden, improve the quality of legislation, facilitate the rapid start-up of new enterprises and create an environment more supportive to businesses. On the labor market, rapid delivery on the recommendations of the European Employment Taskforce, develop strategies for lifelong leaning and active ageing, underpin partnerships for growth and employment, promote environmental sustainability, spread eco-innovations and build leadership in eco-industry and pursue policies which lead to long-term and sustained improvements in productivity through eco-efficiency.

These objectives remain relevant to the EU 2020 strategy currently being considered, described as "an inclusive, smarter, greener economy", which "will require increased policy co-ordination, better synergies through effective subsidiarity, and strengthened partnership between the EU and Member States in the design and delivery of public policies. The integration of different policy instruments is necessary, linking institutional reforms, better regulation, new initiatives and public investment". These are the single market, to be fully exploited, supporting growth through full use of the SGP, reflecting political priorities in the Community budget, and establishing clear governance to make the new strategy effective. Drawing on the new provisions of the Lisbon Treaty, the European Council should steer the strategy but the "Commission would like to see the European Parliament play a significantly greater role in the new governance structure. Beyond its traditional role on the employment and integrated guidelines, Parliament could be encouraged to express views on the EU 2020 strategy before the Spring European Council". The Spring European Council in 2010 should set the strategy on its course for the next 5 years on the basis of a Commission proposal, fixing a small number of headline objectives, and defining the corresponding policy actions to be pursued at EU and Member State level in partnership. It is recognized that, in order to reach its objectives for 2020, the EU must act decisively in the G20 and international forums.

In sum, the EU remains the most ambitious attempt to promote rules of good conduct among its members than the other international organizations. This is why the EU helps draw lessons for other countries and regions. But it must be stressed that other international organizations also played a role in spreading the results of alternative policy paths among their member states. The wide acceptance observed suggests that national policymakers stabilized, liberalized and privatized the economy in part because they saw other policymakers do the same. EU processes derive from a comprehensive "rule book" and call for a greater involvement of many high-level national decision makers than at the other institutions. In this connection, the European institutional architecture is interpreted in a way that favours schemas of flexible integration, which have a voluntary, self selection element. Similarly, the non-compulsory aspect of OECD enhances countries' 
sense of ownership and makes an important contribution to this atmosphere (Macedo, 2003). This is, once again, why in the EU there is peer pressure on the basis of commitments.

Proximity suggests governance responses at the appropriate level, through the combined action of elected officials and civil society (including business). The common good may thus be provided by regional institutions, as long as the various levels of government are appropriately combined. For these reasons schemas of flexible integration have been proposed, where the principle of proximity (or subsidiarity) is generalized from geography to issue areas. This generalization depends on the characteristics of the public good being provided. When there are network externalities with exclusion benefits, as is the case with the Eurosystem (also Schengen), then such flexible integration has a snowballing effect, which may lead initially reluctant states to join in. When there are no exclusion benefits but rather free ride problems, flexible integration does not lead initially reluctant states to join in. This has been observed with respect to common resources (tax or otherwise). Whether policies can have a snowballing effect or not depends, then, on the design of the access to common resources. If the taxation element is restricted in areas, such as in social security reform, it may be easier to spread best practices than if there is an attempt at harmonising systems. Similarly, the financing of public services may be designed to avoid taxation insofar as possible, so that for certain public goods, national legitimacy and democratic accountability at national level may be allowed (Kolliker, 2001).

The recurrent European debate about whether multiple-speed convergence towards union objectives is possible and desirable illustrates the complementarities between global and regional common good. One extreme position in the European debate draws on the view of a unified constitutional state, for which variable geometry is impossible. The other extreme position calls for a set of contractual arrangements, where common institutions are undesirable. From the beginning, the European Community attempted to transcend the rigid intergovernmental nature of the OECD or of the G7 in the direction of supranational institutions like the Commission. But the convergence stopped far short of establishing Community-wide democratic legitimacy. As a consequence, the institutional framework became more and more complex, especially after a Union with three pillars was created in 1992. In the process, flexibility was lost and this is why the draft European constitution approved in 2003 by the Convention for the future of Europe abolished the three pillars and favored schemes of reinforced co-operation, which are still present in the treaty approved in Lisbon at the end of 2007 (which only went into force two years later).

The case for flexible integration can be made by contrasting depth of integration with flexibility. For any given number of member states, there is a trade-off between the freedom to enter into contractual agreements which include some members and exclude others and the ultimate requirement of "one man, one vote" which would be associated with a new state emerging from the integration of all members. The two dimensions of the trade-off are economic efficiency and executive performance, on the one hand, and legal status and legislative activity, on the other. An alternative way of expressing the trade-off which comes closer to the "together alone paradox" refers to forces of 
competition and the forces of co-operation. Zero integration and zero flexibility represents purely intergovernmental co-operation among the same member states, and from there any combination between competition and co-operation can be represented as in Figure 5, adapted from CEPR (1996).

Figure 5 here

Then Europe "a la carte" would be equivalent to a purely contractual institutional design where any combination of subgroups of member states is acceptable, so that the basic intergovernmental principle of equality of member states applies and unanimity in decision making is preserved. During the revisions for the Amsterdam (1996) and Nice (2000) treaties, intergovernmental schemes of reinforced co-operation have been called for among some member states, as their creation still requires unanimity of all member states and their membership is open to all of the member states who qualify. Flexible integration has been the exception rather than rule, however, and no mechanisms for reinforced cooperation were initiated under the Nice treaty, which made them possible in Community, Justice and Home Affairs and even some areas of Common Foreign and Security Policy (CEPR 2001). The institutionalization of the eurogroup of finance ministers in the Lisbon treaty rotates the line of reinforced cooperation in Figure 5. As discussed below, the market turmoil in 2008 and 2009 moved the SGP down towards the "superstate" point, creating an institutional dilemma after the entry into force of the Lisbon treaty. The "together alone" paradox manifests itself even at a very high level of integration, as mentioned at the outset.

To the extent that flexible integration also stresses the portability of the European experience to countries in different stages of economic and financial development, it may not only facilitate enlargement but also a clearer European identity in development cooperation. Greater North-South-South partnership, as envisaged by the AAA and mentioned in section 3.4, may also be easier with the development architecture brought about by the Lisbon treaty.

The failure of the fiscal rules included in the SGP impacted on the characteristics of the public good provided by the Eurosystem, as vigorously argued by the European Commission and Central Bank. In addition, since the Maastricht treaty, the one area where subsidiarity does not apply is the compilation of data - it had been recognised that unless there was agreement on the facts under consideration it would not be possible to move discussion on to the next stage. The widespread use of financial instruments has nevertheless allowed some countries to circumvent the centralization of budget and debt information to the Eurostat, making collaboration with other specialized institutions, notably the IMF, more necessary than it would otherwise be.

The increasing attention of investors to specificities within the eurozone goes beyond the backlash from loose financial regulation which was common to the EU and most of OECD countries. Nevertheless it came as a surprise after some ten years during which sovereign debt instruments of eurozone countries were seen as close substitutes in terms of risk, and the spreads relative to the German Bund were minimal. The effect of the 
Lehmann Brothers failure and the recent volatility are evident in government bond yield spreads as well as credit default swaps, a related market which has grown substantially over the last years ${ }^{34}$. In Figure 6, spreads in 5 year contracts relative to Germany for Greece, Portugal and Spain show Portugal as being closer to Spain than to Greece but nevertheless higher, even though it has a better unemployment outlook. The budgetary situation explains this ranking, which is also found in bank CDS premia ${ }^{35}$.

Figure 6 here

In addition to peer review by commitment, then, perceptions of creditworthiness have become as relevant to regional convergence in the eurozone as economic and financial fundamentals: while Portugal has a better budgetary situation than Greece and a better unemployment outlook than Spain, its fundamentals appear worse. This may be a communication problem, pertaining to hesitations about the SGP but, as Garicano (2010) claims, the crucial dimension is the ability to continue structural reforms so as to restore growth and competitiveness.

\section{3. OECD "surveillance" of non-members and the G20}

Each surveillance framework serves a particular purpose: the ownership by the country is least in the IMF, whereas the EU is most predicated on the common goal of integration (Thygesen 2002, adapted in annex). The mutual surveillance by OECD has the greatest diversity, from overall economic policy to structural and sectoral issues in health, education, corporate governance etc. Aid policies, like most other non-defence policies of member countries, have been subject to peer reviews. Different mechanisms apply to different objectives and to the different mandates of the respective committees which in turn relate to the degrees of commitment from soft co-ordination to mutual help (OECD 2002). The initial collaboration with NEPAD built on considerable work carried out with major emerging markets. Among major non-member countries which have embarked in reform processes, Russia, a G-8 member, was the first to be examined in 1995, and this peer review has taken place several times since. The Economic Survey of 2001 was quite influential in Brazil. It had found the previous review exercise a very interesting and useful experience, in particular in that it had extended the capacity of local institutions to collect the relevant data.

Conversely, in its initial approach to China, OECD mentioned surveillance and got a rather cold reception. A fluctuating relationship ensued, which presents lessons for the way in which international organizations approach countries with the view to offering them assistance. Following a number of years of developing contacts with officials and

\footnotetext{
${ }^{34}$ The implicit arbitrage suggested by a comparison of the two instruments has been demonstrated in the corporate finance literature (e.g. Duffee, 1999 and Hull et al. 2004). I am indebted to my colleague Miguel Ferreira for these references. An alternative explored by Kamin and Pounder (2010) are 5 year CDS premia on financial firms averaged for each country weighted by the firms's total assets.

${ }^{35}$ Kamin and Pounder (2010) report premia for 19 industrial economies, which are both very low and tightly clustered prior to August 2007, progressively rise and become less well clustered, even so the spreads exhibit considerable co-movement as do the stock prices for financial firms. From June 2007 until September 2008, the largest increases in the eurozone were for Ireland, Greece, Austria and Netherlands (about 200), followed by Spain and France (150), Belgium, Portugal and Italy (100).
} 
institutes, relations improved considerably, to the extent that China became an outstanding example of a country that knows how to benefit from the work of international bodies. It is keener on the concept of peer example than peer pressure and is constantly looking for analyses and information. The decisions taken by the authorities are well-informed by conclusions reached on other countries' success and failures (this is borne out, for example, in their caution with regard to capital account and banking sector liberalisation). This shows that the benefits of surveillance and peer review exercises go far beyond the impact of an individual report such as that of 2002. This broader impact, not just for China but for other countries which are considering reforming or rethinking their policies, should not be underestimated. Another contribution, coming from the Statistics Directorate, has been the construction of a cyclical indicator for China, which has allowed a better monitoring of the economy's short term performance.

The peer review process is also a cultural phenomenon -- the regular participation in the peer review process leads to the development of a new frame of mind. This then raises the question of whether local knowledge and local capacity are adequate to challenge the message from the peer review process when it is incorrect, and the collective wisdom is not wisdom at all. There the only guarantee is the quality of the analysis, which is also crucial to the credibility of the international organisations responsible for surveillance; everything should be done to ensure the production of the best possible quality of work. It is also important to remain open to new academic ideas and not to bend with the prevailing view of governments.

Peer pressure may hurt good governance when indicators are not supported by data and analytical knowledge on the issues. The importance of comparable data is crucial to peer pressure. Otherwise wrong conclusions could be reached. This is why the IMF has provided information to feed peer pressure in a regional context such as that which has taken place among finance ministers from Latin America, the Association of South East Asian Nations or the Chang-Mei initiative. The same has happened in the context of the Euro Area's monitoring framework as well as that of the EU as a whole, even before the Lisbon treaty recognized the institutional existence of the Eurogroup.

While multilateral surveillance frameworks apply mostly to macroeconomic issues, there are several cases of peer pressure on structural policies. The efforts involving food security have been especially visible because they preceded the global financial and have been often focused on technical and political rather than economic aspects. Indeed, the lack of agricultural research for development has already threatened agricultural productivity in developing countries after the food and energy crises of the 1970s. Lower productivity and neglect of agriculture exacerbated food price volatility and the energy crisis, leading on to the near financial meltdown of September 2008. The economic crisis was a common threat. Yet no one saw it coming in developed countries and no one knew how to deal with its global nature when it struck. The developing world saw the food and energy crises coming in 2007 but couldn't believe it would spread to credit because bankers, regulators and politicians in advanced countries were supposed to know what they were doing. Once again, the Monterrey Consensus on the MDGs reflected the first time international organizations developed an agenda together, but it largely left out the 
specialized agencies of the UN system. Moreover, as discussed above, the consensus was not implemented and there has been no momentum for global change. The same cannot be said of specific areas, including agricultural and space research, where experiences with culture-based multilateralism were noted at the end of the previous section.

The G20 inherits the flexible structure of the G7 (which does not have a permanent secretariat) but has a renewed mandate for the IMF and, according to the Europe 20202 agenda will receive a greater commitment from European institutions, possibly a single seat for the eurozone. The review of "how national and regional policy frameworks fit together" called for in the Pittsburgh communiqué (Framework for Strong, Sustainable, and Balanced Growth \#5) may well not survive the exit strategies being considered by G20 members - especially if the "group think" of the various institutions involved in multilateral surveillance does not abate. On the other hand, if the various peer review mechanisms become complements rather than substitutes, the new mandate may deepen and widen IMF peer review of its G20 members, something the IMF has not been accustomed to in his previous experience with G7 mandates.

\section{CONCLUSION}

The text claims that, given state capacity and the absence of conflict, developing countries and emerging markets can benefit from multilateral surveillance of the kind often associated with OECD and EU. In other words, global governance needs criteria for the system efficient procedures along the lines of what Robert Triffin proposed for the reform of Bretton-Woods since the 1950s when he was involved with European monetary cooperation (Eichengreen and Macedo 2001). Recent examples of this positive G\&G interaction emphasized by Contzen (2009) are the opportunities for developing countries of the stimulus packages of developed countries, especially through knowledge innovations in the energy and environmental fields.

That being said, the global crisis revealed a "together alone" rooted in "group think" within and between countries. In spite of peer review mechanisms at the OECD and the EU, and of international governance innovation such as the "global partnership for development", not enough attention had been paid to common problems among advanced countries, including financial regulation and supervision in the face of rising asset prices. Increased trade in goods, services and assets led to rising global imbalances between the US and emerging markets with currencies pegged to the dollar, especially China. The resulting volatility in prices of oil and staples had severe implications for poverty alleviation and food security, making the MDGs impossible to reach in 2015, especially in the $\mathrm{AU}$, where a peer review mechanism has been operating for almost ten years.

The paradox, illustrated by the letters of the British Academy to the Queen and the description of the crisis as Western ("blue eyed" for the President of Brazil, brings out into a renewed interest in methodology which goes beyond calls for interdisciplinary research - as long as this research does not disturb the usual "economists tribes", a point that comes across more clearly in the second letter. A perspective based on G\&G interaction to the "together alone" paradox introduces mutual knowledge as essential for 
the global partnership on development and presents in that connection the experience of culture-based multilateralism among members of the CPLP. The focus on Europe as an example of regional governance where peer pressure stems from explicit commitments is embedded in a comparison of multilateral surveillance frameworks in IMF, OECD, EU and AU (Macedo, 2003). The claim is that this may promote the common good, if it also fosters governance innovation - which in turn requires a combination of greater integration and flexibility. In the OECD case, applications of multilateral surveillance beyond members reinforce the claim. While the G20 process is a combination of the various forms of peer pressure, it may enhance the multilateral surveillance framework of the IMF in the direction of mutual accountability. The annex builds on a survey by Thygesen (2002) to compare multilateral surveillance frameworks. Together with the current instability in the eurozone stressed in section 4, it still appears that such frameworks are the most likely to bring about international governance innovation.

The "together alone" paradox goes towards the never again issue addressed by the second letter of the British Academy. An agenda to involve more economic and interdisciplinary work in public debate should be adopted by other academies and research universities. A letter avoiding "group think" of advanced (blue-eyed?) countries might result from a debate encompassing humanities and social sciences as well as natural sciences and from a diversity of CPLP perspectives ${ }^{36}$.

\section{ANNEX MULTILATERAL SURVEILLANCE FRAMEWORKS COMPARED}

\section{Origins of peer pressure at OECD}

The exchanges which take place in the various committees of OECD make the several thousand national civil servants who each year attend those meetings aware of the international complexities and the opportunities for improvement that exist. These exchanges create a sense of community and thereby confidence in the review process. The existence of a community of policy practitioners allows them to bring their local knowledge to bear on the policy review process while also contributing to developing further the conceptual knowledge that they also need. This contribution to meshing conceptual knowledge with local knowledge is key part of the OECD's value-added. It has taken decades to mature and may be difficult to replicate. The Secretariat plays an

\footnotetext{
${ }^{36}$ On the first anniversary of the Queen's visit to LSE, the economics and finance section of ACL agreed to make this a preferred theme for discussion by gathering several recent contributions in addition to the ferragosto presentation mentioned in note 1 above: Nunes (forthcoming); Cardoso (2009), Andrade et al (2009), Cunha (2009). See also Mendes (2009) and Contzen (2010), who are part of the interdisciplinary team of ACL.
} 
important and particular role in OECD peer review exercises because of the quality and uncommon honesty of the background analyses, which are essential for undertaking the reviews. For this reason, it is important to safeguard the quality of those entities within the Secretariat, in particular those engaged in macroeconomic and structural analysis, which are responsible for the peer review process. Not all countries participate as examiners in each of the individual peer review exercises; this reinforces the importance of the Secretariat's contribution and of its integrity. Moreover, the pressure exercised by the published report is much less than the peer pressure exerted in the course of the review process from the visits that the Secretariat pays to each country and, in particular, during the actual examination itself. If this is the case, then the content of the final report and what the country accepts as recommendations are less important than the advice given to policy makers in the course of the review exercise.

On the other hand, IMF missions last at least two working weeks with more people than OECD. This is important, for the determinant of the standing of the institution is the quality of the staff's work. In order to continue to perform well the OECD must maintain its focus on a small number of key structural policy areas for which an analytical framework can be developed. It must avoid being pushed gradually to purely sectoral issues such as energy liberalisation; under the impression that other institutions are doing enough on broad structural reforms and on their link to macroeconomic issues. Seeing OECD as a "reformers" club" has implications for the convergence in economic policy cultures and even in most other areas of non-military policies (Macedo, 2003).

There have been analogies of NEPAD with the Marshall Plan stressing the aid dimension. Yet the analogy is more helpful if the emphasis is on the peer pressure system set up to co-ordinate the implementation of the Marshall plan. Peer pressure encouraged a learning process among European nations, which was inherited by the OECD and the EU. As the choice of the appropriate exchange rate regime illustrates, the circumstances of the particular countries and the topic under consideration matter a great deal for surveillance results: the absence of good data, for example, poses a considerable challenge to the exercise of surveillance and peer review, just like it would to any other initiative for better governance. Related to the need for adequate data and a well-defined analytical method, there is a cultural challenge for credible surveillance, which boils down to the effectiveness of peer pressure. Given the high perception of political risk in Africa relative to other developing areas, greater national capacity and institution building are necessary in order to make peer reviews useful for the purposes of better economic and political governance at the national, regional and global levels.

The generalization of peer reviews seems contained in the G20 Pittsburgh communiqué (\#5 how our national and regional policy frameworks fit together). Yet Africa's exclusion from global governance is most sensitive when the global crisis is deepening and widening: successive meetings of G-20 exacerbate prior concerns about reaching MDGs. In spite of the presence of South Africa, this is a group where poor countries have no voice. Given what we said about the difficulties of going beyond members in OECD surveillance, this might put pressure on the AU Commission to step up the peer review 
mechanism initiated by NEPAD. The issue remains of why potential cooperative solutions are not applied domestically and internationally.

\section{Private macroeconomic surveillance and yardstick competition}

International organizations make projections and macroeconomic analysis, the work done by private sector analysts is of comparable quality and a lot of what they say is similar but it would be rendered much more difficult were the IMF and the OECD to cease producing projections. The effectiveness of the particular framework employed depends on the credibility of the review process. International organizations can add weight to local voices -- even if national think tanks have said something many times, it helps to have a credible external body say it too. Therefore, international organizations must ensure that the analysis and advice presented to the countries is not, and is not perceived to be, either tainted by special interests or weakened by the use of flawed analytical methods. Thus international organizations have a special role to play because of their comparative advantage and greater experience in some areas of evaluation, notably the international environment and interdependencies, and because they have easier access to data. In particular, aside from "bilateral" surveillance of individual member states, the IMF's World Economic Outlook and the OECD Economic Outlook put things into a global perspective, which clearly adds to the surveillance process. Under globalization, this made their work especially credible for the actors involved. With the crisis this credibility has been lost, but the creation of the G20 has helped reinforce the role of IMF and OECD, to the extent that they are more confronted with the "together alone" paradox.

The benefits of information sharing are evident when it comes to the prevention of financial crises. Were it possible to predict crises, those avoided should be counted as successes. Looking at the phenomenon the other way, prediction is not sufficient when there is political sovereignty -- no matter how much pressure is exerted, that substantial degree of freedom cannot be broken. Perhaps the best gauge of success is the extent to which countries are better equipped to withstand crises and whether this is due in part to the existing surveillance mechanisms. This comes out of the debate on the choice of the exchange rate regime, especially in the verifiability of intermediate regimes.

Banks and independent research institutes that evaluate policies and monitor economic performance and policies may fulfill most if not all surveillance functions. The private sector's compliance and risk management expertise is particularly strong in making the case for financial liberalization. More generally, only local actors control the strategic resources - leadership and political capacity - that are essential for governing the policy process. These resources also include particular local knowledge of the nature (complicit or otherwise) of the relationship between the political and business communities, which can be acutely relevant to the policy process. The same can be said about national value systems and how these relate to various policy choices.

The importance of the knowledge bases that exist in the countries under review, notwithstanding those available in international institutions, in particular certain types of technical or conceptual knowledge remain decisive for credible surveillance. In fact there is a tendency for local analysts to compare the prevailing situation with that of 10 or 15 
years earlier when the more relevant and more useful standard of comparison is often the experience of other countries. It is here that the comparative advantage of international institutions resides.

Part of the soft co-ordination that takes place in international fora is information sharing (data produced on a comparable method, details of policies in various sectors and analysis of them). Though it has financial costs, this public good element is not emphasized enough. This is the element that could most easily be transferred from the OECD style of review to others. Some very important objectives could be met by improving information sharing, especially if the bigger players' understanding of the benefits of such information sharing improved.

The issue of whether peer pressure bring about improved performance has been addressed by Besley and Case (1995) in the context of yardstick competition, a term coming from industrial organization which suggests comparing similar regulated firms with each other (Tirole, 1988). For any given firm, the regulator uses the costs of comparable firms to infer a firm's attainable cost level. Conversely, if the regulator equates the price to the marginal cost of the firm itself, then managers have no incentive to reduce cost. Using the costs of comparable firms (or their average excluding that of the firm itself, which serves like a fictitious "shadow firm") prevents the firm's choice to have an effect on the price it gets. As comparable firms may not exist or be observable, a scheme of yardstick competition may not fully overcome moral hazard problems, but it is certainly preferable to the traditional procedure of comparing current and future costs to past performance.

The peer pressure scheme is thus susceptible to manipulation by participating firms but the difficulty in co-operating to impose collusive behavior makes this perverse outcome less likely. Note also that in the case where heterogeneity is observable and can therefore be corrected for, Schleifer (1985) shows that a regulatory scheme based on peer pressure should lead to a superior performance. This implies that the regulator can credibly threaten to make inefficient firms lose money and cost reduction can therefore be enforced. When national objectives are at stake, best practices can thus be achieved, rather than allowing a convergence towards the mean. Conversely, when peer pressure is used to stall reforms, rather than to promote them, the outcome is equivalent to the collusive equilibrium and an alternative yardstick must be devised.

While the result depends on the specifics, it can be safely assumed that if the payoff to good behavior is less than the cost associated with it, there will not be benefits from competition and collusion will be more likely. Costs can come in various forms, from fines to exclusion. As global finance makes benchmarking unavoidable, there is consensus on the need for fiscal rules. As mentioned in the text, the suspension of the SGP in 2003 to avoid penalties for France and Germany during the Intergovernmental Conference on the failed draft constitution made agreement on a new set of rules more necessary but also more difficult. 
The existence of yardstick competition among national policy makers is a consequence of the lack of hierarchy among issues, including military ones, which was the decisive element during the Cold War. Yardstick competition follows from the so-called complex interdependence among OECD countries (Keohane and Nye 1977), which implies that international issues are no longer subject to well defined hierarchies, as was assumed to be the case in the balance of power model of international relations, sometimes described as Westphalian. Moreover, the globalisation of business and the information revolution changed political processes in a way in which soft power became more important in relation to hard power. Credibility became a key power resource, giving more open, transparent organisations an advantage with respect to free information (Keohane and Nye, 2000).

Under complex interdependence, peer pressure did not apply outside the "reformers'club" and this reinforced the view of North vs. South, with the expectation that some form of development assistance would flow from rich to poor countries. Even after the end of the Cold War, the assumption was that there would be no interference in the domestic affairs of poor countries, even when political and economic governance were such that assistance benefited powerful groups and rarely reached the poor. This model of international relations remained in force until the 11 of September attacks. Since then, the emphasis on security has brought back hierarchy, even among likeminded countries, but also the globalisation of solidarity. Legitimacy is certainly required but multilateral surveillance frameworks also require efficiency and this can only be achieved through flexible schemas. National sovereignty has also remained at the heart of the UN system, and co-operation with IMF, World Bank or WTO has been limited to the Monterrey process. Before the global crisis, the role of peer pressure expanded from OECD countries to AU but not to emerging markets like the BRICs.

When there is peer pressure among national policymakers to follow best practices, these are likely to become more and more accepted. Peer reviews have enhanced competition for better macroeconomic and trade policies. Similar benchmarking has begun with respect to structural policies, especially those relating to the regulatory framework. The greater complexity of such policies makes them more susceptible to procrastination, and the same problem has been observed in the EU. This hinders institutional change and makes corporate and political governance more difficult. On the other hand, when applied to corporate strategy, yardstick competition leads to benchmarking exercises which have become common in intergovernmental cooperation.

What is meant by pressure varies with the surveillance framework and the influence of advice might be a matter of managing the process through which the advice is formulated. Moreover, as countries are not just a homogenous block, it is also a question of how the advice is targeted to the different audiences within a country.

\section{Costs and benefits of IMF and OECD surveillance}

As a lending institution, the IMF has particular clout in the case of program countries and to some extent in emerging economies too. The OECD has to rely on the quality of ideas and the relevance of comparative policy analysis. There has been considerable 
discussion over recent years concerning how the supervisory role of the Fund might be strengthened. The idea of liberating the IMF from direct pressure, in particular from the larger countries, was been put forward by Eichengreen et al (1999). It may indeed be hard to complain if some countries, by virtue of their having the capacity and the will to undertake analyses of other countries, exert more influence than others. One way of strengthening the Fund's supervisory role would be to separate the analytical function from lending operations. It is also possible to separate high quality analysis and surveillance and then have the information made available for peer pressure exerted at the regional level, as such pressure is more naturally organized among smaller groups than in the context of global institutions. As argued below, this complementarity also reflects the Monterrey consensus.

In addition to identifying external vulnerabilities and supporting international policy coordination, surveillance as practiced by the IMF may serve as advice, information gathering and dissemination to the public and to policy makers; technical assistance. The core of the policy advice that has been developed over the years though is simply "delivering the message" (Boughton 2001).

In that sense, there is a complementarity between the national discussion which is enriched by the international analysis and the feedback from the particular circumstances of national discussion which enrich international analysis. In the course of preparing country reviews, for example, the interactions with national officials, and their assistance in tailoring the analysis and recommendations to reflect their particular circumstances, are extremely useful. The output of the peer review process is not just the final report. It also includes the interactions in the course of its preparation between national officials, the Secretariat and the Committee. The meaningful standard of the effectiveness of advice, surveillance and peer pressure is then the extent to which it positively influences the domestic debate. Sometimes this can be done through putting forward ideas that have yet to be aired in domestic debate; on other occasions it can be by assisting in the penetration of ideas that have been developed by national research institutes or think tanks.

The scope of IMF surveillance has expanded greatly since that term was introduced with the revision the Fund's articles of agreement in the mid-1970s. At that time it was a matter of "firm" surveillance over the exchange rate policies of members in the post Bretton Woods system of floating rates. The focus was on domestic policies in so far as these influenced the economy's external position. Since then there has been a gradual shift towards advice on the best use of a wide range of policy instruments, whether or not they have a direct bearing on the country's external account or exchange rate. This evolution towards "the promotion and safeguarding of an international code of good conduct in national economic policy" (Guitian 1992) accompanied closer monitoring of national economies by market analysts and rating agencies.

The country coverage widened substantially in the 1990s. Some have called it, without intending any criticism, "mission creep" into additional topics, in particular structural policies. The following six themes now have a prominent part in the Fund's review 
process (except in the least developed countries): labor market policies; product market reform; privatization; financial sector regulation and supervision; trade policy (notwithstanding the fact that the WTO undertakes reviews in this area); and, the environment. The extension of this agenda comes from:

1. political pressure in member countries (for example in the US Congress which has urged greater liberalization);

2. the addition of new members (for example, the membership of the transition economies of the former Soviet Bloc has led to the inclusion of new topics on structural reform);

3. the experience of financial crises; the need for additional longer-term lending facilities (it has been argued that an examination of structural policies is necessary for preparing programs);

4. the IMF "mission creep" in the structural policy area can also be explained by the shift in the analytical focus in economics over the last 15-20 years to medium-term supply-side issues.

Member countries have being going through quite a dramatic paradigm shift which has altered their attitude towards structural policies and the IMF has only accorded a fullscale investment of resources to those structural policy areas which it considers to be important for financial and macroeconomic stability. Examples of this work include financial sector stability assessments, technical assistance for central banking policy and work on tax policy (this latter particularly in developing countries in which IMF is cooperating closely with OECD in an attempt to establish which are the best practices); in many other areas, such as privatization and labor market policies, IMF work has been less systematic than that of OECD with the focus in particular countries largely dictated by the assessment made by country teams.

When the IMF concludes a consultation process, a Public Information Notice is issued by the Board. Until the end of the 1990s, the concluding statements were not published. Their publication may have led to a watering down of their content (though this is difficult to ascertain), but staff do retain considerable influence, notably through the publication of a concluding statement at the end of their missions, the content of which tends to carry through to the Public Information Notice.

The role of Executive Board is circumscribed by the weight of the overall agenda and the number of Article IV reports to consider: approximately 130 country reports, with 11/2-2 hours devoted to each (the Economic Development Review Committee, EDRC by contrast spends a full day even on small countries). Though they do have accumulated experience to bring to bear, the Executive Directors lack the resources to deal adequately with these reports. They depend heavily on comments from capitals which tend to be read out to the letter. As a consequence, there is little give and take in discussions. That said, the countries under examination tend not to exert much pressure to modify the report's conclusions - the only reason that is readily accepted for such a modification is where "market sensitive information" is involved which could be harmful to the country in question. At OECD, by contrast, changes made tend to involve the removal of politically sensitive advice rather than market sensitive information. 
The group of independent experts on IMF surveillance (IMF 1999) noted a direct negative correlation between the size of the country considered and the impact of the advice. A justification for this could lie in the fact that the larger the country the more civil servants, independent research institutes, banks and so forth there are engaged in examining and analyzing the country and so there is less scope for the IMF or indeed any other international institution to say anything new. Examples of direct positive impact are hard to find, even in small countries. The impact is easier to ascertain when a new regime has been introduced following IMF advice, for example, the Czech Republic's exchange rate policy in the early 1990s, and the introduction by Sweden of an inflation target in 1992-93. On the other side, it is clear that countries approaching crises have not been inclined to listen to advice. In the cases of: Brazil in January 1999, Czech Republic in 1996-97, Korea in 1997, Thailand in 1996-97, the Fund did offer advice (and attempted to apply pressure) to modify unsustainable policies but this went unheeded.

A further complication in evaluating the success of the IMF's surveillance is the absence in most cases of relevant policy makers from the examined country when the report is being discussed by the Executive Board. To some extent, this has been responded to by increased transparency which has increased greatly with the publication of the Public Information Notices and the Article IV reports. There exists in this connection a trade-off between confidentiality and transparency: governments, with good reason, object to public discussion of vulnerabilities. Based on the argument that the IMF employs analysts who have the confidence of member countries, the whole process implies "peer pressure by proxy".

That there are areas of overlap and complementarity with the work of OECD should not be taken as a criticism with the way IMF has extended its mandate. The decisive principle governing whether or not this extension is justified is whether a particular element of structural policy is relevant to overall economic performance over the time horizon analysed in the report. As stated in IMF (1999), its senior officials show a very positive attitude towards collaboration with other organisations. In a recent statement, the Executive Board had requested that the staff make more use of the work of other institutions such as the World Bank and the OECD. More could be done to that effect given the insufficient awareness within the IMF of the work on structural themes being planned for discussion at the OECD. As good bilateral surveillance is an essential underpinning for good macroeconomic surveillance, closer co-operation between the IMF and the OECD is both welcome and feasible.

Peer pressure on the basis of commitments (as practised by the EU) or peer pressure by proxy (as practised by the IMF) are mechanisms that illustrate two extremes of multilateral surveillance of national economies. The OECD peer review process has elements of both but it is closer to that of the EU. It is carried out through 68 different monitoring and surveillance activities by 12 directorates (as listed in annex A of OECD 2002) and is therefore extremely diverse and specialised - even though EDRC country reviews could not initially apply to the Euro zone as a whole! In any event, Thygesen (2002) list six distinct advantages of OECD surveillance over that of IMF: 
1. there is more interaction with relevant national policy officials on the basis of the Secretariat's draft reports;

2. the involvement in discussing and modifying reports is greater than that of the Executive Board;

3. the useful element of having two examining countries (which is the closest thing to pure peer pressure that exists in the international system);

4. the subsequent process of revising and approving report, which gives some ownership by the country to the final report (though this redrafting does consume a lot of time);

5. the Organisation's manageable size (IMF 133, OECD 30) and limited diversity of membership (which is particularly beneficial in that it is difficult to keep up to date in technical areas);

6. the continuity (which is typically around 3 years) and experience of the national officials that countries send as representatives (and examiners).

In considering the issue of countries approaching crisis and their receptiveness to advice, one should also consider whether international institutions have given the correct advice. Taking the case of Thailand, according to Blustein (2001), the IMF had clearly indicated that there were problems. Though it was perhaps less successful in spotting the problems in Korea (the OECD had flagged up its concerns), once the Korean crisis had started the Fund's analysis evolved and it put forward policies which have helped the country to get out of its problems in a remarkably short period of time. OECD has occasionally experienced the situation of undertaking an examination of a country at the same time as there has been an IMF programme in place. Thinking back to the review of Turkey at the end of 2000, it was clear that EDRC itself would not want the Survey to undermine an ongoing programme or programme negotiations, while recognising that the underlying analysis should point out areas of policy where reform is needed. Turning to nonprogramme countries, the particular contribution of the OECD resides in its comprehensive analytical coverage, ranging across both macroeconomic and structural policies. The Secretariat has placed increased emphasis on what it judges to be the key areas of structural reform that countries should focus on, rather than trying to give a comprehensive treatment of all issues.

The success of a review exercise is partly dependent on how the officials representing the examined country before EDRC choose to react to the report. On those occasions that officials have been defensive and elected to hold the line on all the existing policies the atmosphere has become rather confrontational; it is probably the case that the most useful report does not emerge under such circumstances. It is when officials acknowledge that the draft report contains politically difficult (in the short term) but ultimately helpful economic advice that the most useful final reports emerge. It would appear indeed that the countries that get the most out of the review process are those that try to toughen up the reports' recommendations in order to use it as an element of persuasion for improving long-term economic performance, which is the point of the exercise. 


\section{References}

African Economic Outlook, Paris: African Development Bank and OECD Development Centre May 2008

Amaral, Luciano (2009), "Old but New Questions back to the passage from Ancien regime to Liberalism", in Macedo et al. (2009a).

Andrade, João Sousa, Fernando Alexandre, Ives Gandra Martins, Paulo Rabello de Castro and Pedro Bação (2009) A crise financeira internacional Estado da Arte, Imprensa da Universidade de Coimbra, September, 195 pp.

Arndt, Christiane and Charles Oman (2006), Uses and Abuses of Governance Indicators, Paris: OECD Development Centre

Barro, Robert J. and José F. Ursúa (2008), "Macroeconomic Crises since 1870", Brookings Papers on Economic Activity.

Barro, Robert J. and Rachel McCleary (2003), Religion and Economic Growth, NBER Working Paper no. 9682.

Besley, Tim and Ann Case, "Incumbent Behavior: Vote Seeking, Tax Setting and Yardstick Competition", American Economic Review, March 1995

Besley, Timothy and Torsten Persson (2009), State Capacity, Conflict and Development, June 1

Bezemer, Dirk J (2009), No One Saw This Coming": Understanding Financial Crisis Through Accounting Models, Groningen University, 16. June

Blanchard, Olivier, Francesco Giavazzi and Filipa Sa (2005), "International investors, the US current account and the dollar", Brookings Papers on Economic Activity, 1

Bliss, Christopher and Jorge Braga de Macedo (1990), editors, Unity with diversity in the European economy: the Community's southern frontier. Cambridge University Press, Cambridge.

Blustein, Paul (2001), The Chastening Inside the Crisis that Rocked the Global Financial System and Humbled the IMF, Washington: Public Affairs

Bonaglia, Federico, Jorge Braga de Macedo and Maurizio Bussolo (2009), How globalisation improves governance, in Linda Yueh (editor), The Law and Economics of Globalisation, Edward Elgar pp. 193-224

Boughton, James (2001), Silent Revolution The International Monetary Fund 197989, Washinton: IMF, 2001

Bourguignon, Francois et al (2008), MDG at mid point, Brussels, September

Braun; Joachim von, Derek Byerlee, Colin Chartres, Tom Lumpkin, Norah Olembo and Jeff Waage (2009), Towards a Strategy and Results Framework for the CGIAR, Washington, December 
Buiter, Willem and Anne C. Sibert (1997) Transition Issues for the European Monetary Union, in De EMU in Breed Perspectief; Preadviezen 1997, Koninklijke Vereniging voor de Staathuishoudkunde, pp. 1-17. Uitgeverij LEMMA BV, Utrecht.

Buti, Marco, Sylvester Eijffinger and Daniele Franco (2003), Revisiting the Stability and Growth Pact: Grand Design or Internal Adjustment? London: CEPR Discussion Paper nr. 3692, January

Cardoso, Jose Luis (2009) "J. M. Keynes e a Grande Depressão da Década de 1930: Lições para o Tempo Presente", Academia das Ciências de Lisboa, 30 April

Causa, Orsetta and Daniel Cohen (2006), The ladder of competitiveness and how to climb it, Paris: OECD Development Centre

CEPR, Flexible Integration, Towards a more effective and democratic Europe, Monitoring European Integration 6, London, 1996

CEPR, Nice Try: should the Treaty of Nice be ratified?, Monitoring European Integration 11, London, 2001

Chinn, Menzie (2009), Tracking the decline in US GDP and consumption, available at. http://www.econbrowser.com/archives/2009/09/tracking_the_co.html

Cohen-Setton, Jérémie and Jean Pisani Ferry (2008), Asia-Europe: The Third Link, European Economy, Economic Papers 352 December (presented at the 8th ASEM conference in Jeju, Korea)

Contzen, Jean Pierre (2009), The effect of the global crisis on the role of Science and Technology (S\&T) for Development, presentation to ELO and CE/CPLP conference, On 18 June

Contzen, Jean Pierre (2010), " Science, Technology and Innovation in the 2010's: towards a better focus on global development? ", presentation to Academy of Science, Lisbon, 28 January

Cooper, Richard (1964), The Economics of Interdependence, New York, Mc Grw Hill

Cunha, Paulo de Pitta e (2009), "A crise económica interna e a crise internacional", Da crise internacional ás questões europeias estudos diversos, Lisboa, August 2009, pp. $11-41$

del Castillo, Graciana (2003), Economic Reconstruction In Post-Conflict Transitions: Lessons for The Democratic Republic of the Congo (DRC), OECD Development Centre Webdoc no. 16, May 2003

Diamond, Douglas and Raghuram Rajan (2009) "Fear of Fire Sales and the Credit Freeze," NBER, University of Chicago Booth School, May.

Dooley, Michael, Peter Garber and David Folkerts-Landau (2005), "Interest Rates, Exchange Rates and International Adjustment", NBER Working Paper

Dornbusch, Rudiger, Daniel Valente Dantas, Rocha Pechman, Roberto de Rezende and Demetrio Simões (1983), "A Model of the Black Market for Dollars." The Quarterly Journal of Economics, February. 
Duffie, Darrell, 1999. Credit swap valuation. Financial Analysts Journal (January/February), 73-87.

Eichengreen, Barry and David Leblang (2006), "Democracy and Globalization", NBER Working Paper No. 12450, August and BIS Working Paper No 219, December.

Eichengreen, Barry and Jorge Braga de Macedo (2001), The European Payments Union and its Implications for the Evolution of the International Financial Architecture in Fragility of the International Financial System - How can we prevent new crises in emerging markets?, edited by Alexandre Lamfalussy, Bernard Snoy and Jérôme Wilson, Brussels: PIE Peter Lang pour Fondation Internationale Robert Triffin, pp. 2542.

Eichengreen, Barry and Kevin O'Rourke (2009), A Tale of two depressions, Vox EU, 1 September

Eichengreen, Barry, Jose de Gregorio, Taka Ito and Charles Wyplosz (1999), An Independent and Accountable IMF, Centre for Economic Policy Research, September 1999.

Emmanuel, Arghiri (1969), L'échange inégal, Paris Maspero

Eurointelligence (2009), Eurozone meltdown?, report at www.eurointelligence.org, 3 April

European Commission (2009), Consultation on the future "EU 2020" strategy, Brussels, 24.11.COM(2009)647 final

European Council (2004), Facing the Challenge: The Lisbon strategy for growth and employment (Kok report), November

Fernández, Raquel (2007), Culture as Learning: The Evolution of Female Labor Force Participation over a Century, New York University, Revised November

Fernández, Raquel (2009), Women's Rights and Development, NYU August

Flandreau, Marc and Frédéric Zummer, The Making of Global Finance 1880-1913, Paris: OECD Development Centre Studies, 2004.

Franco, Francesco (2009) editor, Challenges Ahead for the Portuguese Economy, Lisbon: ICS

Galbraith, James K. (1996), Who's the Real Economist? 8 Dialogues with Paul Krugman, Nov. 6-18, http://www.slate.com/id/3629/

Galbraith, James K. (2010), “Who Are These Economists, Anyway?”, presented at ASSA

Garicano, Luis (2010), Spain has the means to avoid the fate of Greece, Financial Times, 11 March

Garicano, Luis and Richard A. Posner (2005), Intelligence Failures: An Organizational Economics Perspective, CEPR Discussion Paper No. 5186, August

Garoupa, Nuno and Jose Tavares (2009), "Institutions and Portuguese economic History: Implications and (Brief) Applications", in Macedo et al (2009a).

Gisselquist, Rachel and Robert Rotberg (2008), Index of African Governance, Harvard 
Gjerstadt, Steve and Vernon Smith (2009), The Fed and the housing bubble, The Wall Street Journal, 6 April

Goldmann Sachs (2003), Dreaming with Brics, featured in Financial Times 7 October

Guitián Manuel The Unique Nature of the Responsibilities of the IMF IMF Pamphlet no. 46,1992

Haldane, Andrew G (2009), Rethinking the financial network, speech delivered to the Financial Student Association, Amsterdam, April

Hausmann, R. and D. Rodrik. (2003). "Economic development as self-discovery." Journal of Development Economics. 72: 603-633.

Hodgson, Geoffrey M et al. (2009a), Ten leading British Economists write to Her Majesty, claiming that the training of economists is too narrow: "Mathematical technique should not dominate real-world substance." The Business School, University of Hertfordshire, 10 August

Hodgson, Geoffrey M et al. (2009b), Petition for Krugman, Social Capital Gateway, http://www.socialcapitalgateway.org/eng-revitalizingeconomics.html

Hollscher, Jens and Horst Tomann (2004), editors Money, development and Economic Transformation Selected Essays by Hajo Riese, London: Palgrave

Hull, John, Mirela Predesc and Alan White (2004), The relationship between credit default swap spreads, bond yields, and credit rating announcements, Journal of Banking \& Finance 28, 2789-2811

IMF (1999), External Evaluation of IMF Surveillance, report by a group of independent experts (John Crow, Ricardo Arriazu and Niels Thygesen), Washington.

Jedlicki, Claudio (2007), Unequal Exchange, The Jus Semper Global Alliance, Living Wages North and South, September

Kamin, Steven and Laurie Pounder (2010), How did a domestic housing slump turn into a global financial crisis?, Federal Reserve Board, February

Kanbur, Ravi (2004), "The African Peer Review Mechanism (APRM): An Assessment of Concept and Design", Politikon, November.

Keohane, Robert and Joseph Nye (1977), Power and Interdependence, Little Brown.

Keohane, Robert and Joseph Nye (2000), "Power and Interdependence in the Information Age" in Elaine Ciulla Kamarck and Joseph Nye, editors, democracy.com? Governance in a Networked World, Hollis Publishing Company, NH

Kindleberger, Charles (1962), Foreign Trade and the National Economy, New Haven: Yale University Press

Kolliker, Alkuin (2001), Bringing together or driving apart the union? Towards a theory of differentiated integration, preprints aus der Max Planck Projektgruppe Recht der gemeinschaftsguter, Boon 5 
Kouri, Pentti (1983), "Balance of Payments and the Foreign Exchange Market: A Dynamic Partial Equilibrium Model", J. Bhandari and B. H. Putnam (editors), Economic Interdependence and Flexible Exchange Rates, MIT Press.

Kouri, Pentti and Jorge Braga de Macedo (1978), Exchange Rates and the International Adjustment Process, Brookings Papers on Economic Activity, September.

Krugman, Paul (1983), "Oil and the Dollar", J. Bhandari and B. H. Putnam (editors), Economic Interdependence and Flexible Exchange Rates, MIT Press

Krugman, Paul (1991), History vs. Expectations, Quarterly Journal of Economics, May

Krugman, Paul (1995), Peddling Prosperity, New York: Basic

Krugman, Paul (1996a), Of Economists and Liberals, The American Prospect, December

Krugman, Paul (1996b), Economic Culture Wars: For reasons explained below, the editor dares not add a subtitle to this article, Oct. 25, http://www.slate.com/id/1911/.

Krugman, Paul (2008), Outside Advice then and now, in Franco (2009)

Krugman, Paul (2009), "Why did economists get it so wrong?", The New York Times Magazine 2 September

Krugman, Paul (2010), Crises, presented at ASSA

Kuttner, Bob (1996), Peddling Krugman, The American Prospect, September

Lo, Andrew (2009), The Adaptive Markets Hypothesis and Financial Crisis, Perimeter Institute for Theoretical Physics, Waterloo, Conference on Economic Crisis, May 1

Macedo, Jorge Braga de (2001), "Globalization and Institutional Change: A Development Perspective", in Globalization Ethical and Institutional Concerns, edited by Louis Sabourin and Edmond Malinvaud, Tha Pontifical Academy of Social Sciences, Acta 7, Vatican City, pp. 223-267.

Macedo, Jorge Braga de (2003), Peer review and public private partnership among developing countries, report to the OECD Secretary General, December

http://www.globalcentres.org/programs/globalgov/bellagio03/Background_5_reportsgnxt .pdf

Macedo, Jorge Braga de (2009), Economic Advice and Regime Change in Portugal, in Franco (2009), pp. 201-229

Macedo, Jorge Braga de and Luís Brites Pereira (2007), Diferencialidade Portuguesa na Globalização, Negócios Estrangeiros, 11(2), July, pp. 223-236.

Macedo, Jorge Braga de and Luís Brites Pereira (2009), "Cape Verde and Mozambique as development successes in Sub-Saharan Africa", presented at NBER conference on African development successes

Macedo, Jorge Braga de, Colm Foy and Oman (2002) editors Development is back, Paris: OECD, 2002

Macedo, Jorge Braga de, Daniel Cohen and Helmut Reisen (2001), editors, Don't fix don't float, OECD: Paris 
Macedo, Jorge Braga de, Joaquim Oliveira Martins and Luís Brites Pereira (2007a), "How Freedoms interact with globalization", presented at conference on globalization and democracy, Princeton University, September 27-28, revision in progress

Macedo, Jorge Braga de, Luciano Amaral, Álvaro Ferreira da Silva and António Castro Henriques (2009) editors Nove Ensaios na tradição de Jorge Borges de Macedo, Lisboa: Tribuna da História em colaboração do CG\&G e IICT, 314 pp.

Macedo, Jorge Braga de, Luís Brites Pereira, Joaquim Pina and João Jalles (2007b), "Relatório sobre CPLP e Objectivos de Desenvolvimento do Milénio", IICT, October

Maddison, Angus (2001). The world economy: a millennial perspective, Paris: OECD

Maddison, Angus (2007), Contours of the World Economy 0-2030 AD, Oxford University Press

Maloney Michael T. and J Harold Mulherin (2003), The complexity of price discovery in an efficient market: the stock market reaction to the Challenger crash, Journal of Corporate Finance, Vol. 9, $\mathrm{n}^{\circ}$ 4, September

Mantero, Francisco and Nuno Santos (2002), Report on the Public Private Partnership in Mozambique pilot project, October (Portuguese version available)

Mendes, Rui Vilela (2009), Academia das Ciências de Lisboa, 30 April

NEPAD (2001), New Partnership for African Development, October available at www.nepad.org.

Nunes, Manuel Jacinto (2009), “Alguns aspectos da crise económica”, Anuário de Economia (forthcoming)

Nye, Joseph (2002). "A Whole New Ball Game" Financial Times Dec 28

OECD (2002) Peer Review: A tool for co-operation and change, Paris

OECD (2003), Globalisation and Governance: Main Results of the OECD Development Centre Programme of Work 2001/2002, Paris: OECD, May

Persaud, Avinash and Metcalfe, M (2002), Is it Really Stupid? The markets perspective on the Stability \& Growth Pact and prospects for its reform, paper presented at the Euro 50 Group meeting held in Paris on 27 November.

Persson, Torsten and Guido Tabellini (2006), "Democratic capital the nexus of political and economic change", NBER Working Paper No. 12175.

Reinhart, Carmen (2010), This Time is Different Chartbook: Country Histories on Debt, Default, and Financial Crises, NBER Working Paper No. 15815, March

Reinhart, Carmen and Kenneth Rogoff (2009), This time is different: eight centuries of financial folly, Princeton University Press, Princeton.

Reinhart, Carmen and Kenneth Rogoff (2010), Growth in a time of debt, NBER Working Paper 15639, January

Reinhart, Carmen, Kenneth Rogoff and Rodrigo Savastano (2003) Brookings Papers on Economic Activity, Spring 2003 
Sachs, Jeffrey and Andrew Warner (1994), Economic Convergence and Economic Policies, NBER Working Paper

Sachs, Jeffrey and Andrew Warner (1995), Economic Reform and the Process of Global Integration, Brookings Papers on Economic Activity

Sah, Raaj and Joseph Stiglitz (1986), The Architecture of Economic Systems: Hierarchies and Polyarchies, The American Economic Review, Vol. 76, No. 4 September, pp. 716727

Schleifer, Andrei "A theory of yardstick competitition", Rand Journal of Economics, vol. 16, no 3, Autumn 1985, pp. 319-327.

Sirico, Robert (2009), "Pope on Love in Truth", The Wall Street Journal, 13 July

Spielmann, David and Rajul Pandya-Lorch (2009), Highlights from millions fed, proven successes in agricultural development, Washington: International Food Research Institute

Stiglitz, Joseph, Amartya Sen and Jean-Paul Fitoussi (2009), Report by the Commission on the Measurement of Economic Performance and Social Progress, Paris, September

Tavares, Jose and Romain Wacziarg (2001) "How democracy affects growth", European Economic Review, 45: 1341-1378.

Thygesen, Niels (2002), Peer pressure as part of surveillance by international institutions, available at http://www.oecd.org/pdf/M00031000/M00031293.pdf

Tirole, Jean (1988), The theory of industrial organization, Cambridge, Mass: MIT Press

Tornell, Aaron and Philip Lane, The Voracity Effect, The American Economic Review, March 1999, 22-46.

UNECA (2002) African peer review (APR) mechanism: Frequently asked questions, October

World Bank (2003), Towards Country-led Development: Synthesis Report, Washington, October 
Figure 1 The Fed (left scale) and the housing bubble (right)

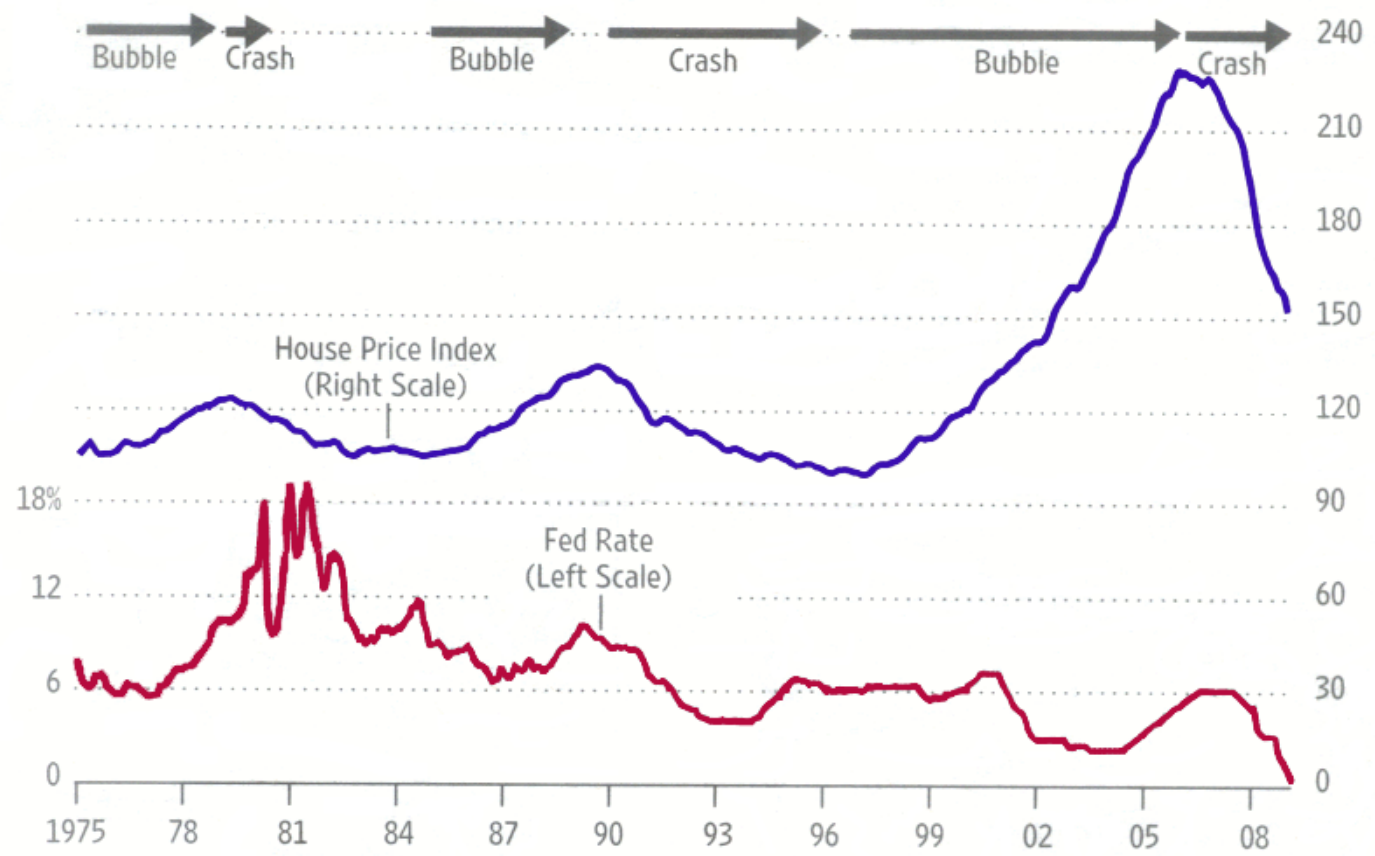

Source: Gjerstadt \& Smith (2009)

Figure 2 Tracking the decline in US GDP \& consumption

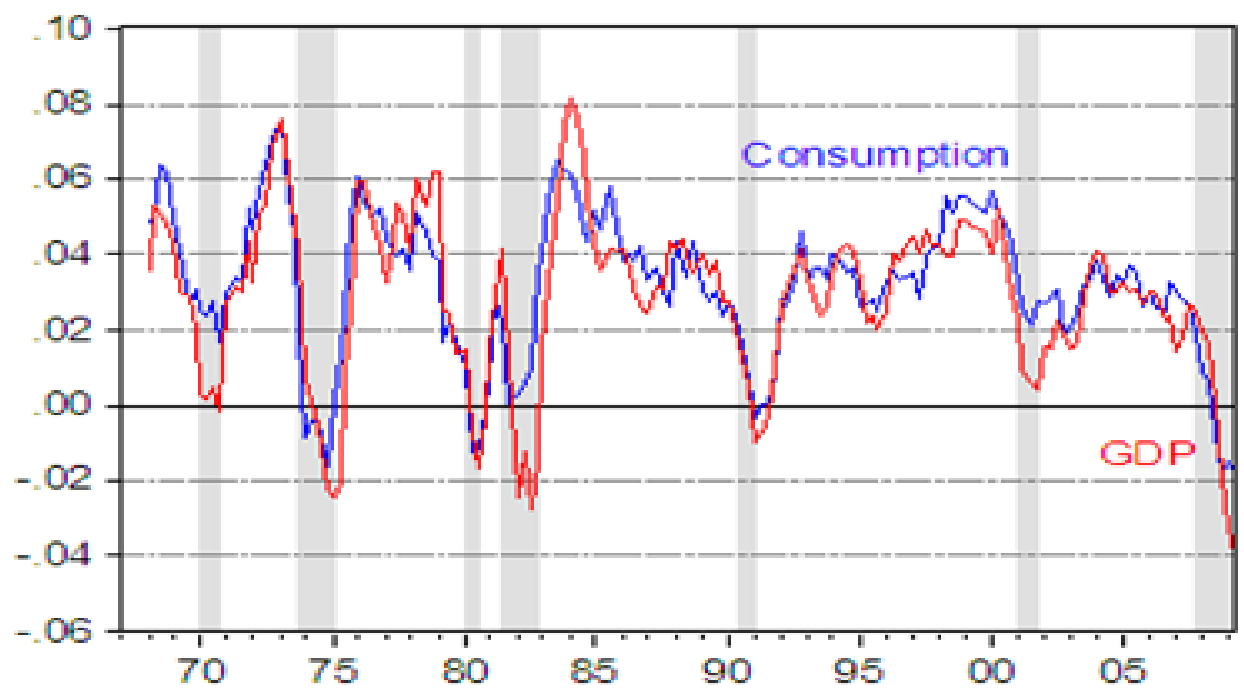

Source: Chinn http://www.econbrowser.com/archives/2009/09/tracking_the_co.html 
Figure 3 Shares in World GDP

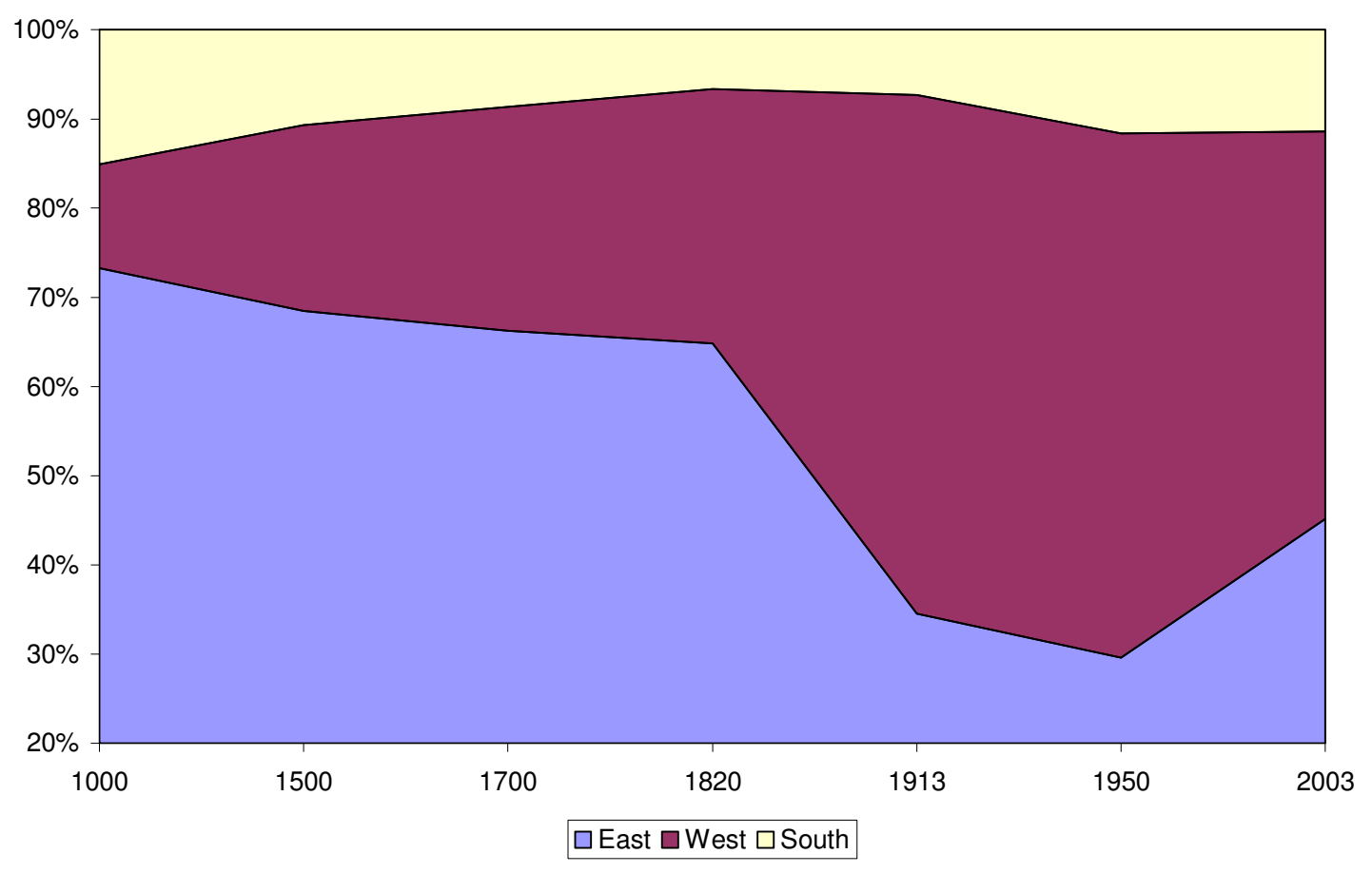

Source: Maddison data base, definitions in text

Figure 4

\section{SHARES IN WORLD POPULATION}

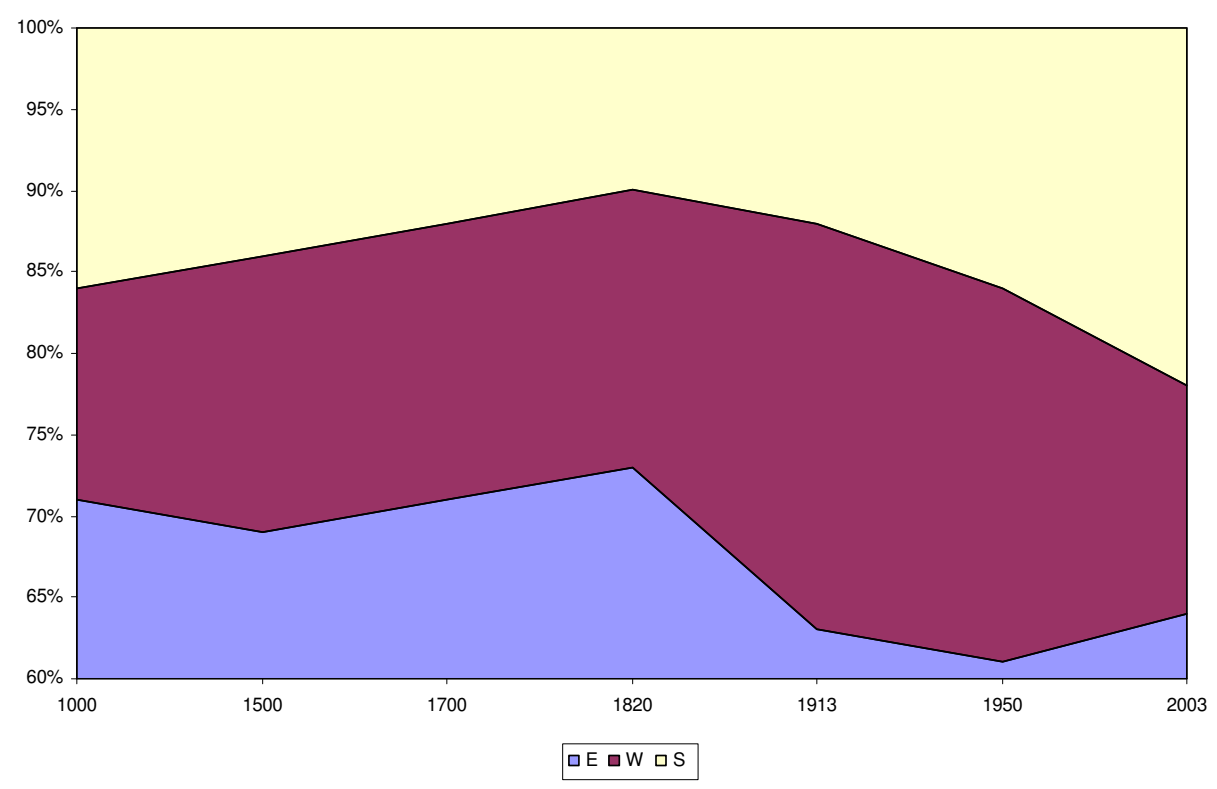

Source: Maddison data base 
Figure 5 Flexible integration

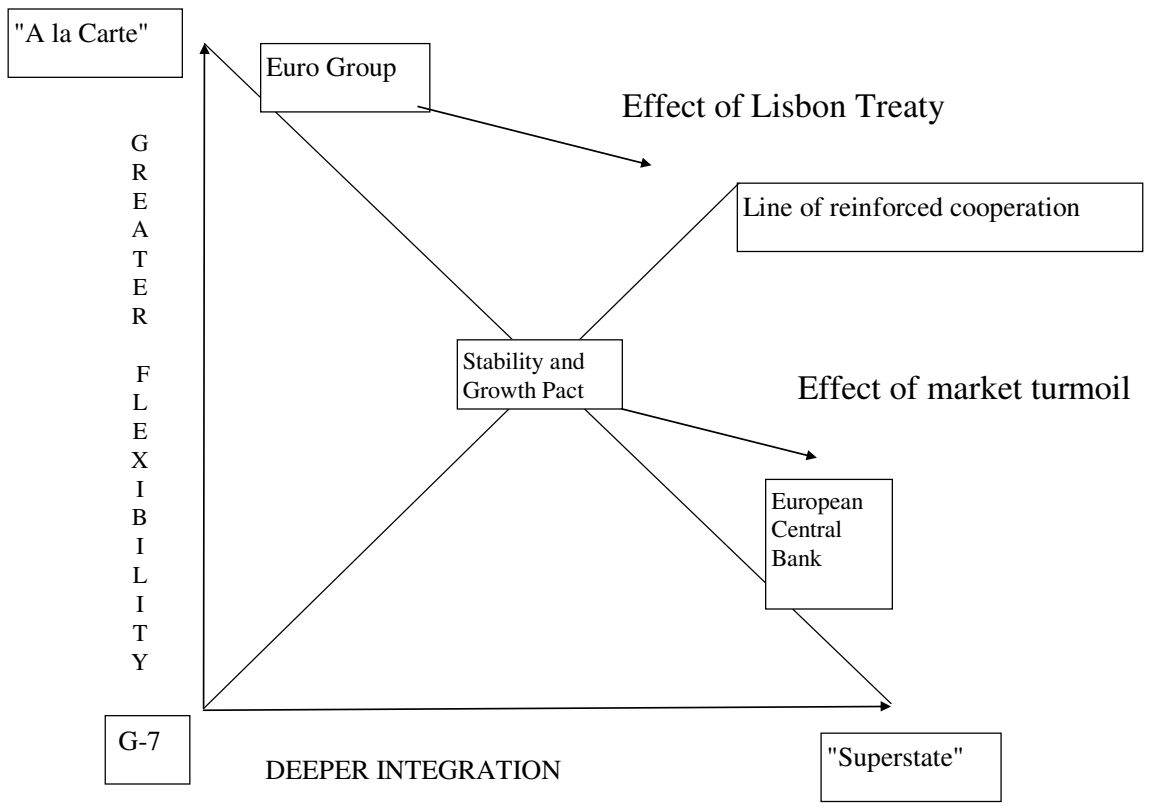

Source: Adapted from CEPR (1996)

Figure 6 Default risk in the euro periphery 
Spreads relative to Germany on 5 year \$ CDS 10 September, 2008 - 9 March, 2010 (basis points) - Greece - Portugal - Spain

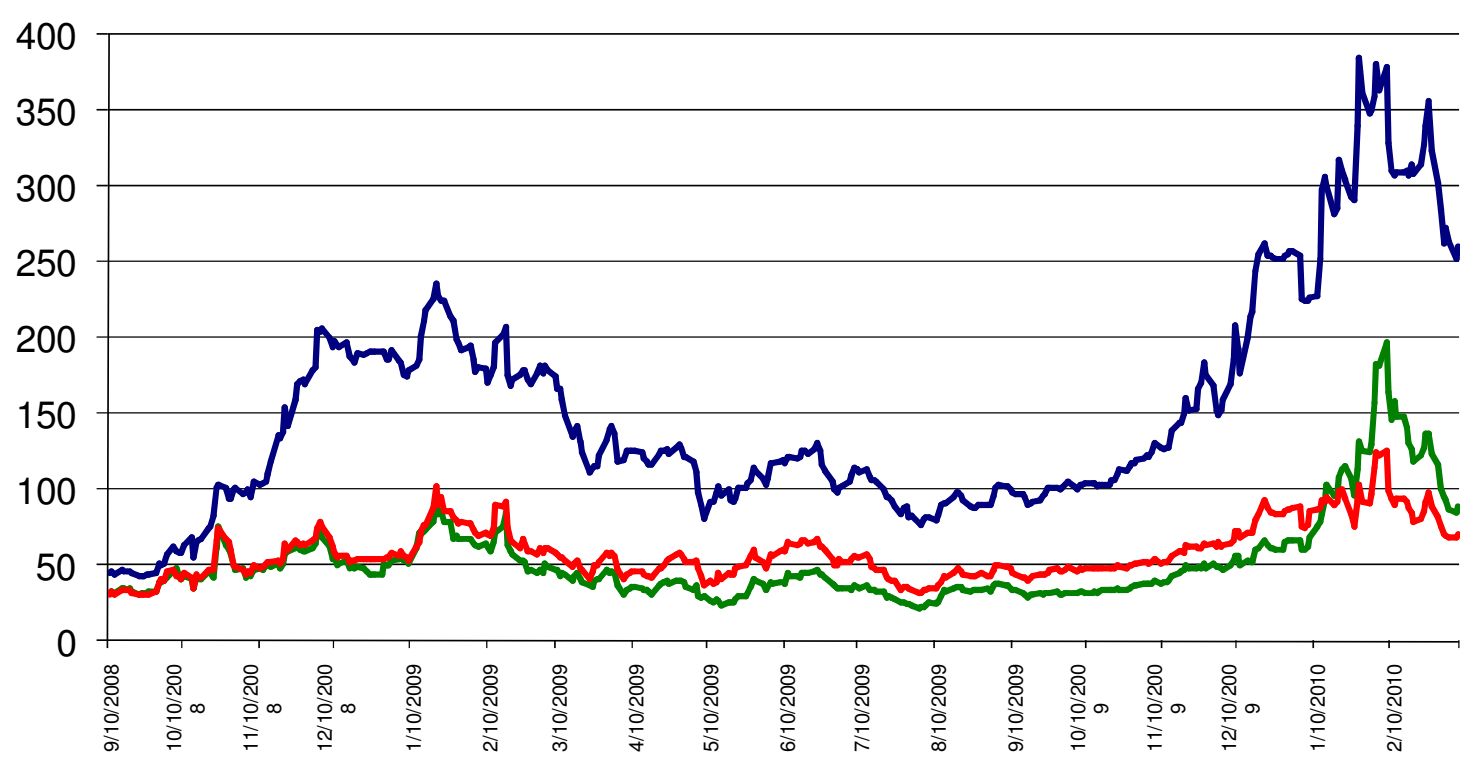


Table 1 Dominance matrix

\begin{tabular}{|l|l|l|l|l|}
\hline & US (NA) & EU & $\begin{array}{l}\text { EAST } \\
\text { ASIA }\end{array}$ & ROW \\
\hline Defense & YES & NO & NO & NO \\
\hline Finance & YES & YES & NO & NO \\
\hline Trade & NO & YES & YES & NO \\
\hline Land & NO & NO & NO & YES \\
\hline
\end{tabular}

Table 2 Regional Finance to Trade Ratios

\begin{tabular}{|l||l||l|l||l|l||l|}
\hline & EA & EA & EU & EU & NA & NA \\
\hline & 1996 & 2006 & 1996 & 2006 & 1996 & 2006 \\
\hline $\begin{array}{l}\text { Finance* to Trade** } \\
\text { Ratio }\end{array}$ & 3 & 3 & 6 & 7 & 8 & 9 \\
\hline
\end{tabular}

[*] Intra-regional foreign asset holdings and liabilities excluded; data available only until 2004; [**] Intra-regional trade excluded;

Source: Cohen-Setton and Pisani-Ferry (2008) 
Table 3 Bankrupcies since independence

\begin{tabular}{|l|l|l|l|l|}
\hline & & & & \\
& & & & \\
& $1300-812$ & $1813-90$ & $1891-008$ & Total \\
\hline Spain & 7 & 7 & 0 & 14 \\
\hline France & 9 & 0 & 0 & 9 \\
\hline Brazil & & 0 & 8 & 8 \\
\hline Germany & 3 & 3 & 2 & 8 \\
\hline Austria & 4 & 1 & 2 & 7 \\
\hline Portugal & 1 & 6 & 0 & \\
\hline Greece & - & 3 & 2 & 5 \\
\hline UK & 2 & 0 & 0 & 2 \\
\hline Netherlands & 0 & 1 & 0 & 1 \\
\hline
\end{tabular}

Source: Reinhart and Rogoff (2009, tables 6.1-2-4-6, pp. 86-99) updating Reinhart, Rogoff and Savastano (2003)

Table 4 Years in Default (1800-), Credit Rating (1979-)

\begin{tabular}{|l|c|c|c|c|}
\hline & Yrs Def & Yrs Bkng & Rating & $\Delta$ Rating \\
\hline Portugal & 11 & 2 & 85 & 33 \\
\hline Spain & 24 & 8 & 90 & 19 \\
\hline Greece & 51 & 4 & 81 & 19 \\
\hline Austria & 17 & 2 & 95 & 9 \\
\hline Netherl & 6 & 2 & 95 & 5 \\
\hline Brazil & 25 & 9 & 61 & 4 \\
\hline UK & 0 & 9 & 94 & 3 \\
\hline France & 0 & 12 & 94 & 3 \\
\hline Germany & 13 & 6 & 95 & -4 \\
\hline
\end{tabular}

Source: Reinhart and Rogoff (2009, table 10.2, p. 149 and table 17.2, p. 285) 